NASA/TM-1999-209133

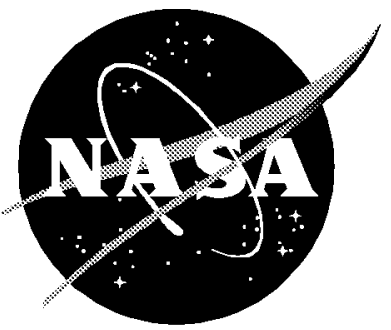

Analyses of Fatigue Crack Growth and Closure Near Threshold Conditions for Large-Crack Behavior

J. C. Newman, Jr.

Langley Research Center, Hampton, Virginia 


\section{The NASA STI Program Office ... in Profile}

Since its founding, NASA has been dedicated to the advancement of aeronautics and space science. The NASA Scientific and Technical Information (STI) Program Office plays a key part in helping NASA maintain this important role.

The NASA STI Program Office is operated by Langley Research Center, the lead center for NASA's scientific and technical information. The NASA STI Program Office provides access to the NASA STI Database, the largest collection of aeronautical and space science STI in the world. The Program Office is also NASA's institutional mechanism for disseminating the results of its research and development activities. These results are published by NASA in the NASA STI Report Series, which includes the following report types:

- TECHNICAL PUBLICATION. Reports of completed research or a major significant phase of research that present the results of NASA programs and include extensive data or theoretical analysis. Includes compilations of significant scientific and technical data and information deemed to be of continuing reference value. NASA counterpart or peer-reviewed formal professional papers, but having less stringent limitations on manuscript length and extent of graphic presentations.

- TECHNICAL MEMORANDUM. Scientific and technical findings that are preliminary or of specialized interest, e.g., quick release reports, working papers, and bibliographies that contain minimal annotation. Does not contain extensive analysis.

- CONTRACTOR REPORT. Scientific and technical findings by NASA-sponsored contractors and grantees.
- CONFERENCE PUBLICATION. Collected papers from scientific and technical conferences, symposia, seminars, or other meetings sponsored or co-sponsored by NASA.

- SPECIAL PUBLICATION. Scientific, technical, or historical information from NASA programs, projects, and missions, often concerned with subjects having substantial public interest.

- TECHNICAL TRANSLATION. Englishlanguage translations of foreign scientific and technical material pertinent to NASA's mission.

Specialized services that complement the STI Program Office's diverse offerings include creating custom thesauri, building customized databases, organizing and publishing research results ... even providing videos.

For more information about the NASA STI Program Office, see the following:

- Access the NASA STI Program Home Page at http://Www.sti.nasa.gov

- Email your question via the Internet to help@sti.nasa.gov

- Fax your question to the NASA STI Help Desk at (301) 621-0134

- Telephone the NASA STI Help Desk at (301) 621-0390

- Write to: NASA STI Help Desk NASA Center for AeroSpace Information 7121 Standard Drive Hanover, MD 21076-1320 
NASA/TM-1999-209133

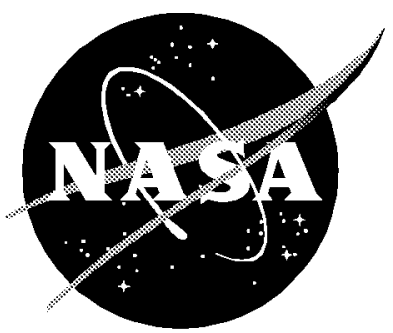

\section{Analyses of Fatigue Crack Growth and Closure Near Threshold Conditions for Large-Crack Behavior}

J. C. Newman, Jr.

Langley Research Center, Hampton, Virginia 
Available from:

NASA Center for AeroSpace Information (CASI) 7121 Standard Drive

Hanover, MD 21076-1320

(301) 621-0390
National Technical Information Service (NTIS) 5285 Port Royal Road

Springfield, VA 22161-2171 (703) 605-6000 


\title{
ANALYSES OF FATIGUE CRACK GROWTH AND CLOSURE NEAR THRESHOLD CONDITIONS FOR LARGE-CRACK BEHAVIOR
}

\author{
J. C. Newman, Jr. \\ NASA Langley Research Center \\ Hampton, Virginia \\ USA
}

\begin{abstract}
A plasticity-induced crack-closure model was used to study fatigue crack growth and closure in thin 2024-T3 aluminum alloy under constant-R and constant- $\mathrm{K}_{\max }$ threshold testing procedures. Two methods of calculating crack-opening stresses were compared. One method was based on contact- $\mathrm{K}$ analyses and the other on contact crack-openingdisplacement (COD) analyses. These methods gave nearly identical results under constant-amplitude loading but under load-reduction (threshold) simulations the contact-K analyses gave lower crack-opening stresses than the contact-COD method. Crackopening stresses determined from the compliance-offset method agreed with results from the COD analyses. But crack-growth predictions tend to support the use of contact-K analyses. Crack-growth simulations showed that remote closure can cause a rapid rise in opening stresses in the near threshold regime for low-constraint (plane-stress) and high applied stress levels for both low and high stress ratios. Under low applied stress levels and high constraint (near plane-strain), a rise in opening stresses was not observed near threshold conditions. But crack-tip-opening displacements (CTOD) were of the order of measured oxide thicknesses in the 2024 alloy and these oxide layers may have an influence on opening stresses. In contrast, under constant- $\mathrm{K}_{\max }$ testing the CTOD near threshold conditions were an order-of-magnitude larger than measured oxide thicknesses. Residualplastic deformations under both constant- $R$ and constant- $K_{\max }$ threshold simulations were several times larger than the expected oxide thicknesses. Thus, residual-plastic deformations, in addition to oxide and roughness, play an integral part in threshold development.
\end{abstract}

\section{INTRODUCTION}

In 1970, Paris [1] proposed a method to determine very slow fatigue-crack-growth rates and showed the development of a fatigue-crack-growth threshold, $\Delta \mathrm{K}_{\mathrm{th}}$. Later, Saxena et.al [2] and an ASTM Task Group developed a standard test method for nearthreshold crack-growth-rate measurements. The use of thresholds in the design of structures subjected to cyclic loading has greatly increased over the past 20 years. 
Especially in components subjected to high-cyclic loading, such as engines or propellers, crack propagation to failure occurs very rapidly and thresholds play a large role in life prediction. Damage tolerance methods are currently being proposed for use under highcyclic fatigue conditions and large-crack thresholds are controlling the design of these components. However, continued work in the threshold regime over the past decade suggests that current methods of defining the fatigue-crack-growth threshold are influenced by the test method and reveal significant differences between fatigue-life predictions based on small-crack growth rate behavior compared to that based on largecrack (threshold) behavior. These issues raise questions on the use of the thresholds in the design of structures subjected to cyclic loads. The various forms of fatigue-crack closure (plasticity, roughness and oxide debris) have all been proposed to occur during the threshold development. Thus, a complete understanding of thresholds must address all of the possible forms of closure.

Elber [3] observed that fatigue-crack surfaces can contact each other even during tension-tension cyclic loading and he subsequently developed the crack-closure concept. This observation and the explanation of crack-closure behavior revolutionized damagetolerance analyses and began to rationally explain many crack-growth characteristics, such as crack-growth retardation and acceleration. Since the discovery of plasticity-induced crack closure, several other closure mechanisms have been identified, such as oxide- [4] and roughness-induced [5] closure, which appear from the literature to be more relevant in the near-threshold regime. However, observations of fatigue-crack surfaces near threshold conditions, which show roughness and/or oxides, do not readily show the extent of the residual-plastic deformations (without strain measurements or X-ray diffraction) in relation to oxide thicknesses and roughness contributions.

The objective of this paper is to use a two-dimensional, plasticity-induced crackclosure model [6,7] to study fatigue-crack growth and closure in a thin-sheet 2024-T3 aluminum alloy under constant- $\mathrm{R}$ and constant- $\mathrm{K}_{\max }$ threshold testing procedures. Analyses were made on a middle-crack tension, $\mathrm{M}(\mathrm{T})$, specimen using the modified stripyield model, as shown in Figure 1. Two methods of calculating crack-opening stresses were compared. One based on contact- $\mathrm{K}$ analysis and the other on contact crackopening-displacement (COD) analyses. Comparisons were made between these calculation methods and values determined from remote crack-mouth-opening displacements (CMOD) using the 1 or $2 \%$ compliance-offset method. Crack-growth simulations, using the crack-closure model, of threshold testing procedures were made for a variety of conditions. The effects of constraint (plane-stress/plane strain), stress ratio, stress level, and load-shedding rates on crack growth and closure were studied. The 
crack-tip-surface displacements, near threshold conditions, were computed to show the extent of the residual-plastic deformations. An assessment of the role of plasticity-induced closure and residual-plastic deformations, in addition to oxide debris, in threshold development was made.

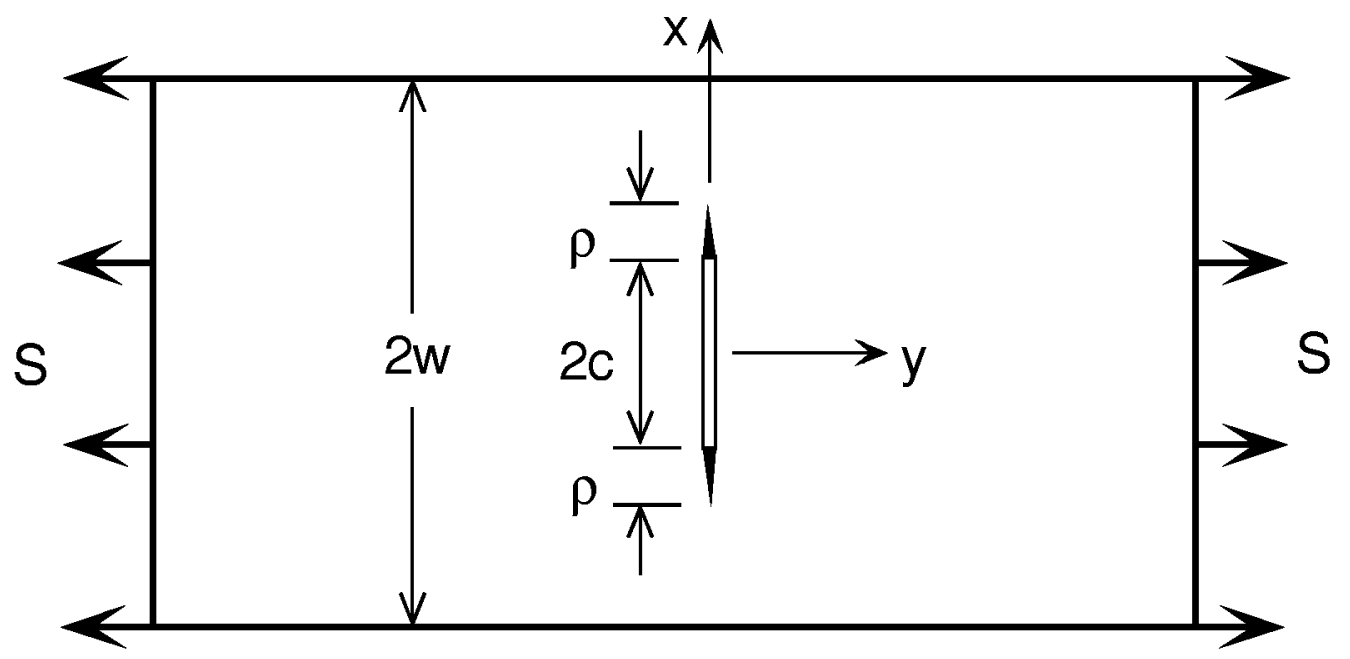

Figure 1 - Crack configuration analyzed with strip-yield model.

\section{Plasticity-Induced Crack Closure Model}

The plasticity-induced crack-closure model, shown in Figure 2, was developed for a through crack in a finite-width plate subjected to remote applied stress. The model was based on the Dugdale strip-yield model [8] but modified to leave plastically deformed material in the wake of the crack. The details of the model are given elsewhere (see Newman [6,7]) and will not be presented here. One of the most important features of the model is the ability to model three-dimensional constraint effects. A constraint factor, $\alpha$, is used to elevate the flow stress $\left(\sigma_{\mathrm{o}}\right)$ at the crack tip to account for the influence of stress state $\left(\alpha \sigma_{\mathrm{o}}\right)$ on plastic-zone sizes and crack-surface displacements. The flow stress $\sigma_{\mathrm{o}}$ is taken as the average between the yield stress $\sigma_{\mathrm{ys}}$ and ultimate tensile strength $\sigma_{\mathrm{u}}$ of the material. For plane-stress conditions, $\alpha$ is equal to unity (original Dugdale model); and for simulated plane-strain conditions, $\alpha$ is equal to 3. Although the strip-yield model does not model the correct yield-zone shape for plane-strain conditions, the model with a high constraint factor is able to produce crack-surface displacements and crack-opening stresses quite similar to those calculated from three-dimensional, elastic-plastic, finiteelement analyses of crack growth and closure for finite-thickness plates [9].

The calculations performed herein were made with FASTRAN Version 3.0. The modifications made to FASTRAN-II (Version 2.0 described in reference 7) were made to 
improve the crack-opening stress calculations under variable-amplitude loading, to improve the element "lumping" procedure to maintain the residual plastic deformation history, and to improve computational efficiency. From the model, CMOD was calculated at the centerline of the model $(\mathrm{x}=0)$. In the application of the model, about 25 to 30 elements are created along the crack surface during threshold test simulations. There were 10 elements in the plastic zone (crack-tip element, $\mathrm{j}=1$, is $1 \%$ of the plastic-zone size).

The crack-tip-surface element $(j=n)$ was $2 \%$ of the cyclic plastic zone $(\omega)$. Crack-surface displacements were calculated from the elements along the crack surface, as shown in Figure 2(b). The crack-opening stress, $S_{0}$, is normally calculated from the contact stresses, shown in Figure 2(b), by equating the applied stress-intensity factor at $S_{O}$ to the stress-intensity factor caused by the contact stresses at $S_{\min }$ [6]. This value is denoted as $\left(\mathrm{S}_{\mathrm{o}}\right)_{\mathrm{k}}$. Herein, the crack-opening stress was also calculated from the contact-COD analysis [10]. From a displacement analysis, the applied stress required to "fully" open the crack surfaces, $\left(\mathrm{S}_{\mathrm{o}}\right)_{\mathrm{d}}$, was calculated.
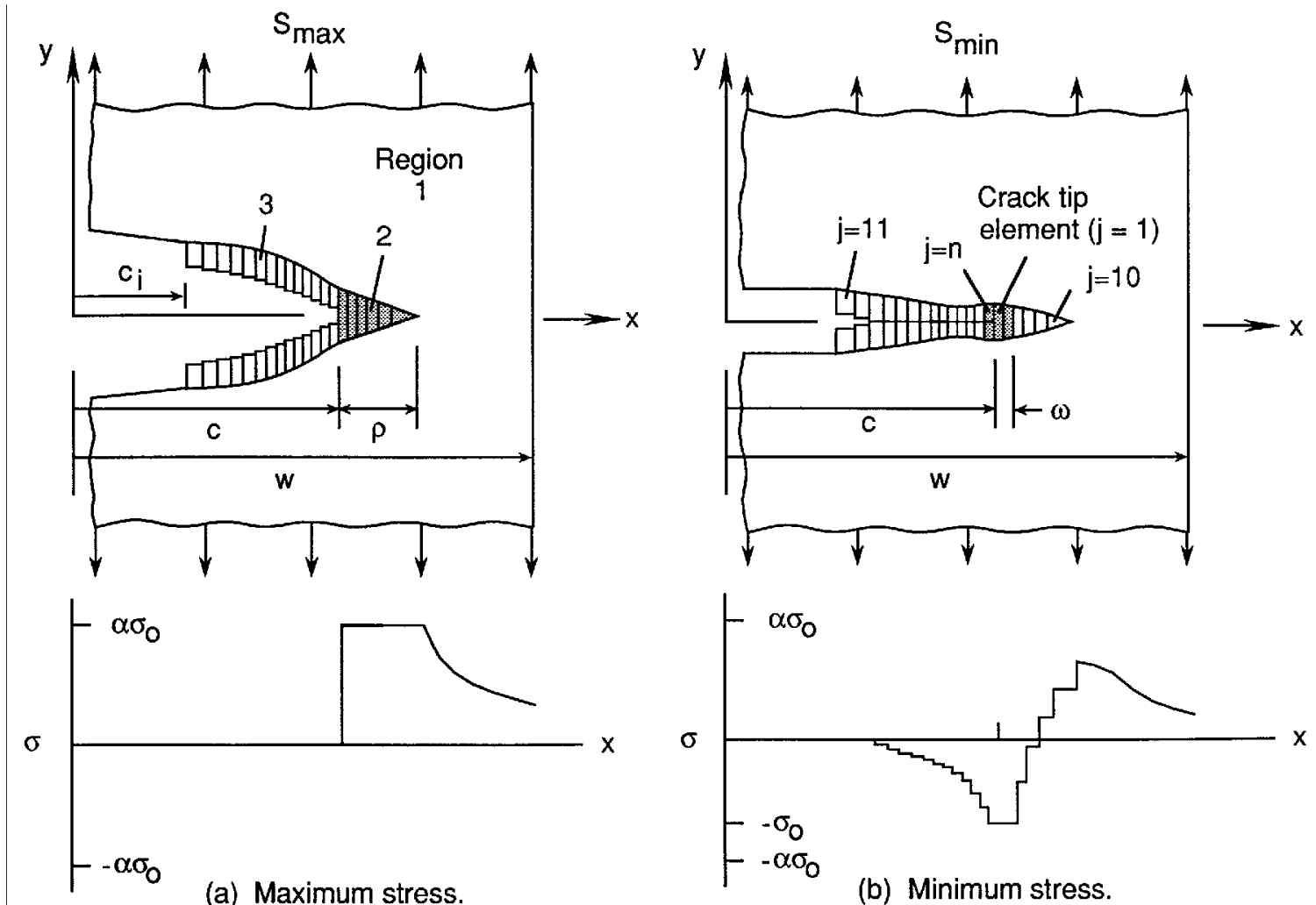

Figure 2 - Schematic of strip-yield model at maximum and minimum applied loading. 


\section{EFFECTIVE STRESS-INTENSITY FACTOR RANGE AGAINST CRACK- GROWTH RATE RELATIONS}

The linear-elastic effective stress-intensity factor range developed by Elber [3] is

$$
\Delta \mathrm{K}_{\mathrm{eff}}=\left(\mathrm{S}_{\max }-\mathrm{S}_{\mathrm{o}}\right) \mathrm{F} \sqrt{ }(\pi \mathrm{c})
$$

where $\mathrm{S}_{\max }$ is the maximum stress, $\mathrm{S}_{\mathrm{o}}$ is the crack-opening stress, $\mathrm{F}$ is the boundarycorrection factor and $\mathrm{c}$ is the crack length. The crack-growth rate equation proposed by Elber states that the crack-growth rate is a power function of the effective stress-intensity factor range (like the Paris equation). However, fatigue crack-growth rate data plotted against the $\Delta \mathrm{K}$ or $\Delta \mathrm{K}_{\mathrm{eff}}$, commonly show a "sigmoidal" shape. To account for this shape, the power relation was modified by Newman [6] to

$$
\mathrm{dc} / \mathrm{dN}=\mathrm{C}\left(\Delta \mathrm{K}_{\mathrm{eff}}\right)^{\mathrm{n}} \mathrm{G} / \mathrm{H}
$$

where $\mathrm{G}=1-\left(\Delta \mathrm{K}_{\mathrm{o}} / \Delta \mathrm{K}_{\text {eff }}\right)^{\mathrm{p}}$ and $\mathrm{H}=1-\left(\mathrm{K}_{\max } / \mathrm{C}_{5}\right)^{\mathrm{q}}$. The function $\mathrm{G}$ accounts for threshold variations with stress ratio and the function $\mathrm{H}$ accounts for the rapid crackgrowth rates approaching fracture. The term $\Delta \mathrm{K}_{\mathrm{o}}=\mathrm{C}_{3}\left(1-\mathrm{C}_{4} \mathrm{~S}_{\mathrm{o}} / \mathrm{S}_{\max }\right)$. The parameter $\mathrm{C}_{5}$ is the cyclic fracture toughness. As cracked specimens are cycled to failure, the fracture toughness is generally higher than the toughness for cracks grown at a low load and then pulled to failure. This is caused by the shielding effect of the plastic wake [11]. The cyclic fracture toughness $\left(\mathrm{C}_{5}\right)$, like the elastic fracture toughness $\left(\mathrm{K}_{\mathrm{Ie}}\right)$, is a function of crack length, specimen width, and specimen type. A two-parameter fracture criterion [12] was used to model the fracture process (predict $\mathrm{C}_{5}$ as a function of crack length and specimen width). Although the fracture term, $\mathrm{H}$, was selected to fit high-rate data approaching fracture, the term has recently been used to help explain $\mathrm{K}_{\max }$ effects at low rates [13].

The threshold function, $\mathrm{G}$, was originally selected because crack-opening stresses from constant-amplitude loading could not collapse the low-rate data onto a unique $\Delta \mathrm{K}_{\mathrm{eff}} \mathrm{f}^{-}$ rate curve. The $\left(\Delta \mathrm{K}_{\mathrm{eff}}\right)_{\text {th }}$ values for threshold tests were a function of stress ratio, $\mathrm{R}$. Developing models to predict threshold behavior would allow better correlation of data and the determination of intrinsic material crack-growth properties in the near-threshold regime. Many investigators (see for example, refs. 14-15) have shown experimentally that the stress-intensity factor threshold under load-reduction schemes can be explained by crack-closure behavior (or a rise in $\mathrm{S}_{\mathrm{o}} / \mathrm{S}_{\max }$ ratio as the threshold is approached). Recently, Donald and Paris [16], using a remote displacement gage, have shown that the 
measured crack-opening loads were "not" able to correlate low stress-ratio test data with high stress-ratio (non-closure) data because the measured opening loads were much too high. But what caused the rise in the $\mathrm{S}_{\mathrm{o}} / \mathrm{S}_{\max }$ ratio from the threshold tests? And why does the remote displacement gage method fail to measure the appropriate opening value to correlate crack-growth rate data? A number of suggestions have been advanced to explain the rise in the $\mathrm{S}_{\mathrm{o}} / \mathrm{S}_{\max }$ ratios. Among these are the mismatch of crack-surface features observed by Walker and Beevers [5]; the corrosion product formation on the crack surfaces, as observed by Paris et al. [4] and measured by Vasudevan and Suresh [17]; and plasticity-induced crack-closure during load reduction, as calculated by Newman [10]. The mismatch of crack-surface features and corrosion products on the crack surfaces can cause the surfaces to come into contact at a higher load than the load for a crack without mismatch or corrosion products. The mode of crack growth near the threshold is a combination of Mode I and II (tensile and shear). The mixed-mode crack growth, and permanent plastic deformations, causes an irregular crack-surface profile and mismatch, and, consequently, the possibility of premature crack-surface contact. The analytical treatment of crack closure due to crack-surface mismatch or corrosion products on the crack surface is beyond the scope of the present paper. Only the effects of residualplastic deformations were considered in this paper. However, an assessment on the effects of oxide-debris thickness in relation to computed crack-tip-surface displacements are made for threshold testing. A possible reason for the remote displacement gage measuring the incorrect opening load during threshold testing will be addressed in the next section.

\section{CRACK GROWTH AND PLASTICITY-INDUCED CLOSURE ANALYSES}

In the following sections, the plasticity-induced crack-closure model, FASTRAN, was used to simulate fatigue-crack growth under constant-amplitude loading and the ASTM Standard Test Method for Measurement of Fatigue Crack Growth Rates (E-647) loadreduction (threshold) testing procedure. The local crack-tip and remote (CMOD) displacements near thresholds were studied under low (plane-stress) and high (plane-strain) constraint conditions. The two methods (contact-K and COD) to calculate crack-opening stress levels were compared. Using the contact-K analyses, the effects of constraint, stress ratio, stress level and load-shedding rates on crack-opening stresses were studied. A brief discussion on possible three-dimensional residual-plastic-deformation effects on closure is presented.

\section{Constant-Amplitude Loading}

The original crack-closure model [6] used the contact-K analysis to calculate crackopening stresses under constant-amplitude loading. But under variable-amplitude loading, remote or intermittent closure occurs, such as after a single-spike overload, leaving an open 
gap between the closed surfaces and the crack tip. Thus, a crack-opening displacement (COD) method to calculate crack-opening stresses was also developed by Newman [10]. Here the opening stress was the applied stress level required to "fully" open the crack surfaces. A comparison of the two methods for constant-amplitude loading is shown in Figure 3 for three levels of constraint at $S_{\max } / \sigma_{o}=0.2$. Here the two methods gave essentially the same results. The solid curves are the crack-opening stress equations developed to fit these results [18]. Comparisons of crack-growth predictions with test data under variable-amplitude loading tend to support the use of the contact-K analysis method [6]. But the contact-COD method may have bearing on crack-opening measurements recently made by Donald and Paris [16]. This will be presented and discussed later.

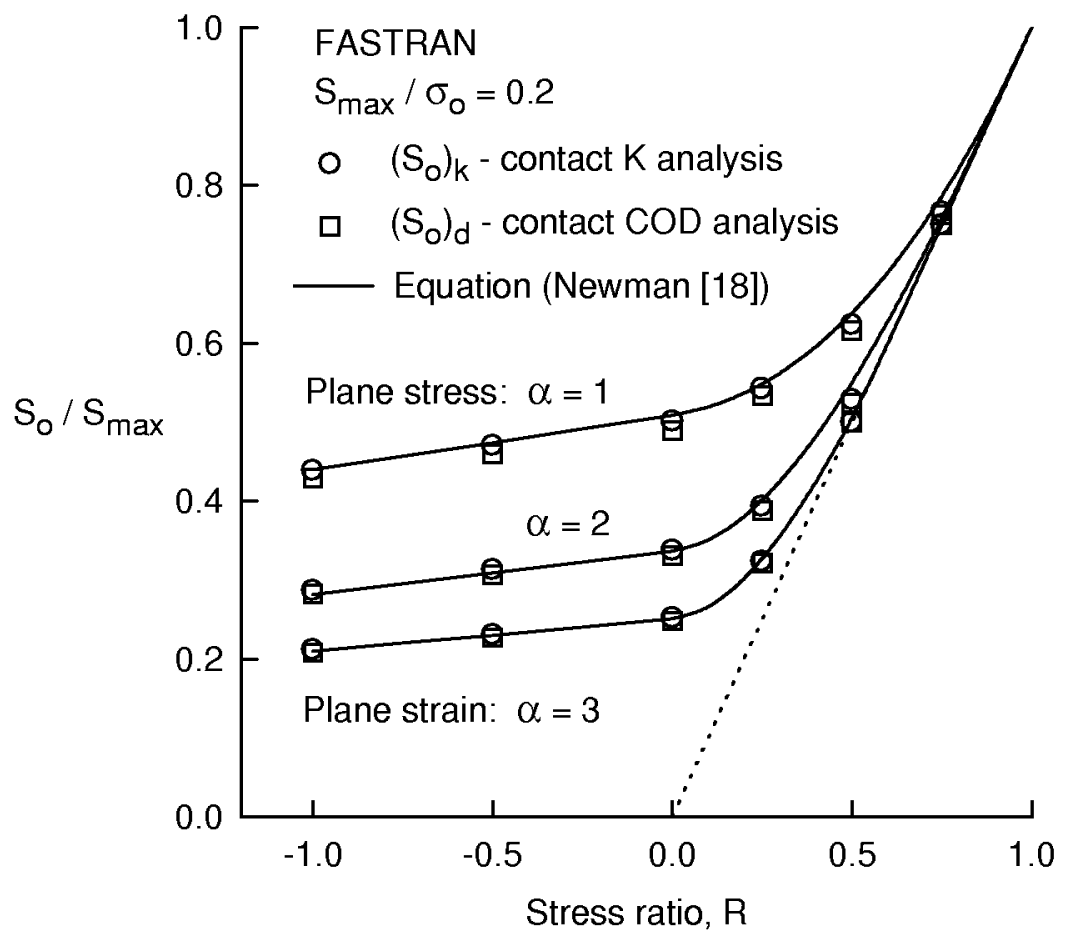

Figure 3. Calculated crack-opening stresses from contact-K and contact-COD analyses under constant-amplitude loading.

\section{Load-Reduction Method}

As previously mentioned, Saxena et.al [2] and other ASTM colleagues developed a standard test method for near-threshold fatigue-crack-growth-rate measurement. The load-reduction procedure was based on stress-intensity factors changing at an exponential rate. A typical load-reduction example is shown in Figure 4. The ratio of the current applied stress, $S_{\max }$, to the initial applied stress, $\left(S_{\max }\right)_{i}$, is plotted against crack length. 
The crack length $\left(\mathrm{c}_{\mathrm{i}}\right)$ at the initiation of the load-reduction procedure was $20 \mathrm{~mm}$ in a large middle-crack tension specimen. The solid curves are based on a constant rate of change in normalized plastic-zone size with crack extension. The normalized K-gradient, $(\mathrm{dK} / \mathrm{dc}) / \mathrm{K}$, was $-0.08 \mathrm{~mm}^{-1}$ for the upper solid curve, as recommended. This is equivalent to about a $5 \%$ change in stress every $0.5 \mathrm{~mm}$ of crack extension, as shown by the stairstep lines. The standard also allows a $10 \%$ change every $0.5 \mathrm{~mm}$ of crack extension, if computerized, smooth load-reduction capability is not available. This is equivalent to a normalized K-gradient of $-0.2 \mathrm{~mm}^{-1}$, as shown by the lower solid curve. The standard load-reduction scheme (upper solid curve) will be used unless otherwise noted.

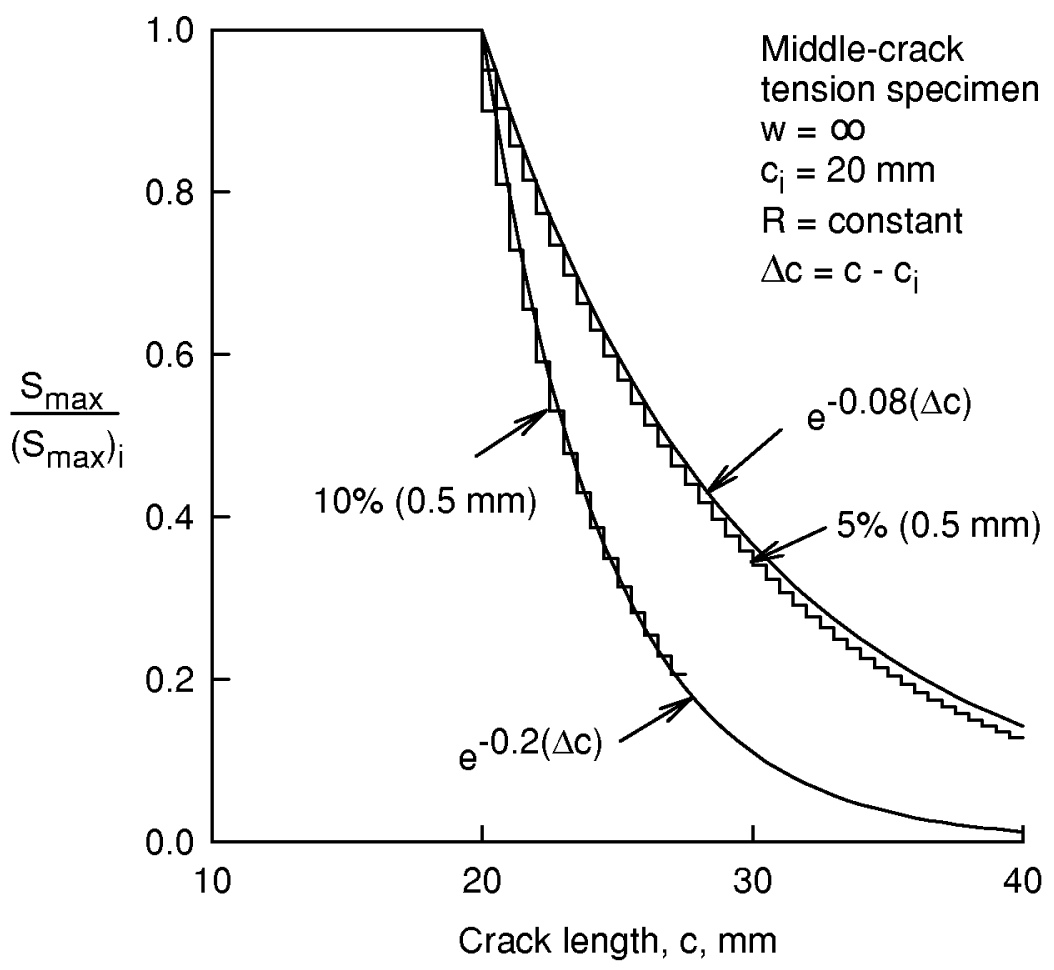

Figure 4. Load-reduction procedures for low-crack-growth rates.

Local and Remote Displacements - Simulated crack-growth analyses under the standard ASTM load-reduction procedure were made after precracking an $\mathrm{M}(\mathrm{T})$ specimen for about 13 $\mathrm{mm}$ from a sawcut of $13 \mathrm{~mm}$ in length. These analyses were conducted at low and high constraint for low $(R=0)$ and high $(R=0.7)$ stress-ratio conditions. The applied stress level was chosen so that a high stress-intensity factor condition would exist at the start of the loadreduction procedure. The reason that this level was chosen was because some recent threshold testing results in the literature appear to have initiated the load-reduction test at high $\mathrm{K}$ levels and the resulting $\Delta \mathrm{K}_{\mathrm{th}}$ values are showing specimen-size and specimen-type effects [19]. 
Plane-stress conditions - Figure 5 shows the local COD's along the crack surfaces for a plane-stress simulation at $\mathrm{R}=0$. The sawcut, fatigue precracking (constant-amplitude loading at $\left.\left(\mathrm{S}_{\max }\right)_{\mathrm{CA}}=115 \mathrm{MPa}\right)$, and load-reduction regions are as indicated along the $\mathrm{x}$-axis. The solid and dashed curves show the results at maximum and minimum applied stress, respectively. These results show that even at maximum applied stress $(9 \mathrm{MPa})$ the crack surfaces were still in contact near the start of the load-reduction regime. The solid symbols shows the displacement at the centroid of the elements in the model. Although not apparent from the figure, the crack surfaces at the crack tip $(\mathrm{c}=51 \mathrm{~mm})$ are closed at minimum load.

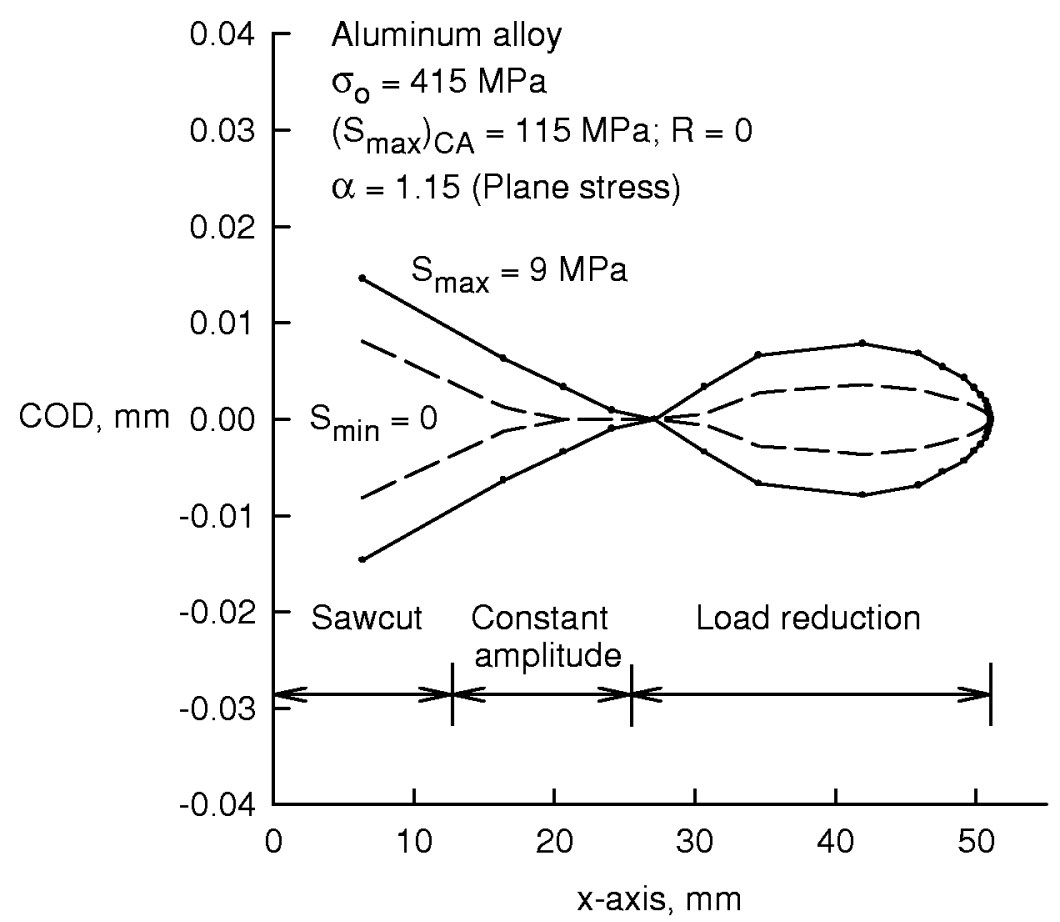

Figure 5. Crack-surface displacements after load reduction under plane-stress conditions.

The remote cyclic CMOD results at $\mathrm{c}=51 \mathrm{~mm}$ are shown in Figure 6 as the solid curve. Loading and unloading followed the same curve. The dotted line is the linear-elastic behavior. Of course, the contact-COD method gave an opening-stress ratio of 1.0 (crack surfaces never opened) but the contact-K analysis gave a value $\left(\mathrm{S}_{\mathrm{O}}\right)_{\mathrm{k}} / \mathrm{S}_{\max }$ of about 0.68 . The open symbol denotes when the crack tip opened. The dashed line shows the $\left(\mathrm{S}_{\mathrm{o}}\right)_{\mathrm{kCA}}$ results from a constant-amplitude simulation at the same stress-intensity factor. In an effort to assess whether the contact-K analysis was an appropriate value to use in a crack-growth analysis, the cyclic crack-tip displacements for both the load-reduction (solid curve) and constant-amplitude (dashed curve) simulations are shown in Figure 7. These results show that the crack-tip-cyclic 
displacement (or cyclic strain) for the load-reduction case was less than that for the constantamplitude case. Of course, the contact-COD value, $\left(\mathrm{S}_{\mathrm{o}}\right)_{\mathrm{d}}$, is not appropriate because the crack tip experienced cyclic plastic deformations and, presumably crack-tip damage and crack growth. Thus, the appropriate opening value to use would be higher than the constantamplitude case, but whether the $\left(\mathrm{S}_{\mathrm{O}}\right)_{\mathrm{k}}$ value is appropriate would require further study of crack-growth rates against cyclic displacements or cyclic hysteresis energies. This is beyond the scope of the present study. However, reference 13 showed a close relationship between the traditional $\Delta \mathrm{K}_{\mathrm{eff}}$ approach and the cyclic crack-tip displacements for a steel and an aluminum alloy for constant-amplitude loading, which would support the use of the $\left(\mathrm{S}_{\mathrm{o}}\right)_{\mathrm{k}}$ values.

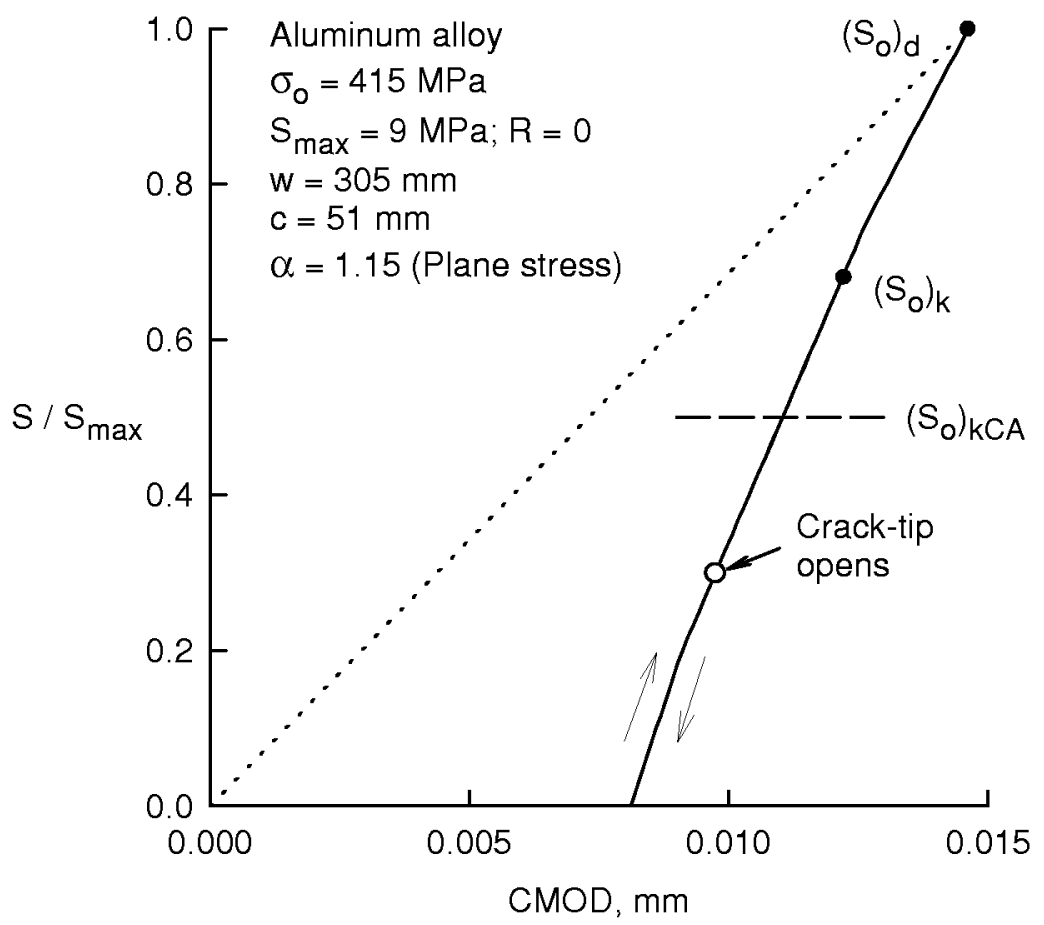

Figure 6. Remote crack-mouth-opening displacements after load reduction under plane-stress conditions. 


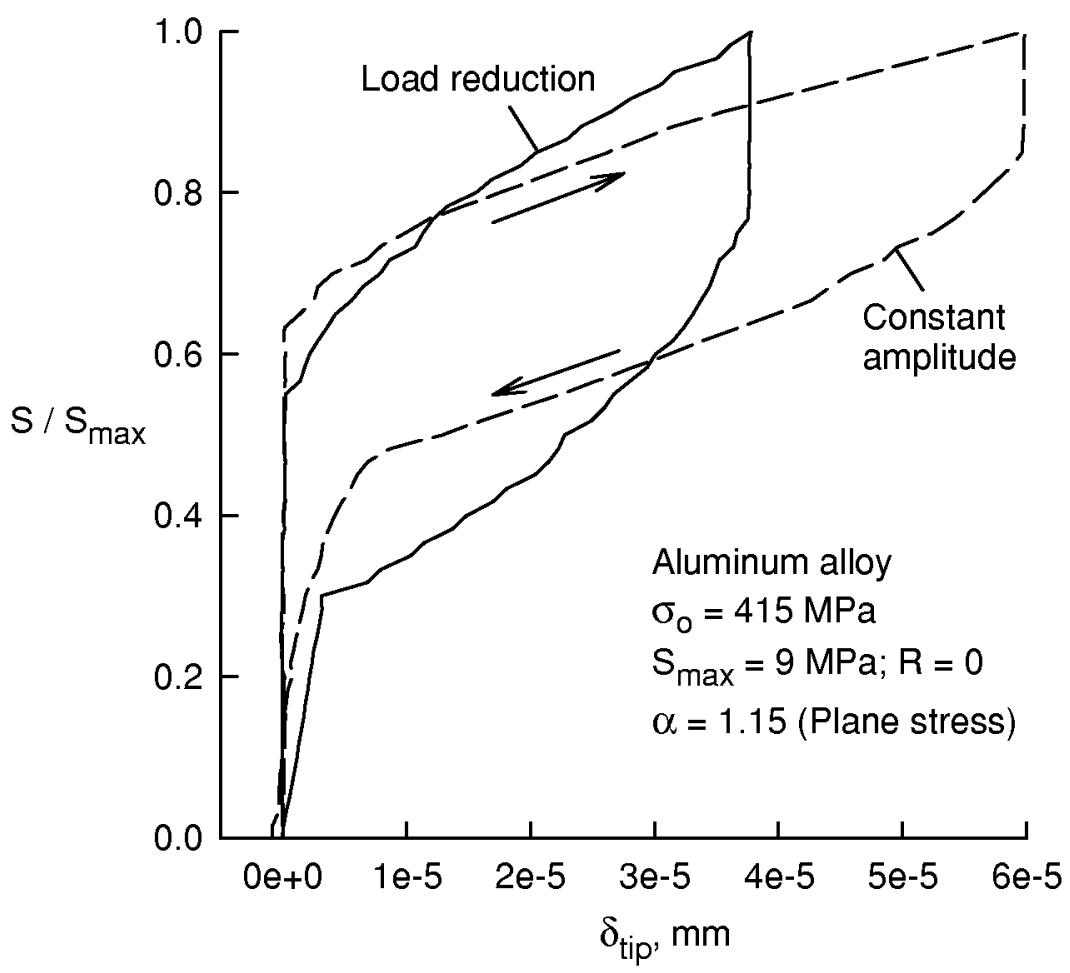

Figure 7. Crack-tip deformations for a cycle of loading during constant-amplitude loading and load-reduction crack-growth simulations.

High-constraint conditions - To simulate more realistic crack-tip conditions, a higher constraint factor $(\alpha=2)$ was used in the same load-reduction case $(\mathrm{R}=0)$ as previously shown. The local COD's along the crack surfaces are shown in Figure 8. Again, the solid and dashed curves show the results at maximum and minimum applied stress, respectively. In contrast to the plane-stress case, these results show that the crack surfaces were not in contact at the maximum applied stress ( $7 \mathrm{MPa}$ ). But at minimum load, the crack surfaces near the start of the load-reduction procedure and at the crack tip $(\mathrm{c}=54 \mathrm{~mm})$ were closed.

The remote cyclic CMOD results at $c=54 \mathrm{~mm}$ are shown in Figure 9 as the solid curves. Loading and unloading, again, followed the same curve and the dotted line is the linear-elastic behavior. The dashed line shows the $\left(\mathrm{S}_{\mathrm{o}}\right)_{\mathrm{kCA}}$ results from a constant-amplitude simulation at the same stress-intensity factor. Here the contact-COD method gave an opening-stress ratio of about 0.62 and the contact-K analysis gave a value $\left(\mathrm{S}_{\mathrm{o}}\right)_{k} / \mathrm{S}_{\max }$ of about 0.4 (slightly higher than the constant-amplitude value). Using these remote displacements and the 1 or $2 \%$ compliance-offset method gave an opening stress value very nearly equal to the $\left(\mathrm{S}_{\mathrm{o}}\right)_{\mathrm{d}}$ value. This may be why the remote displacement gage may measure an incorrect opening load during threshold testing. 


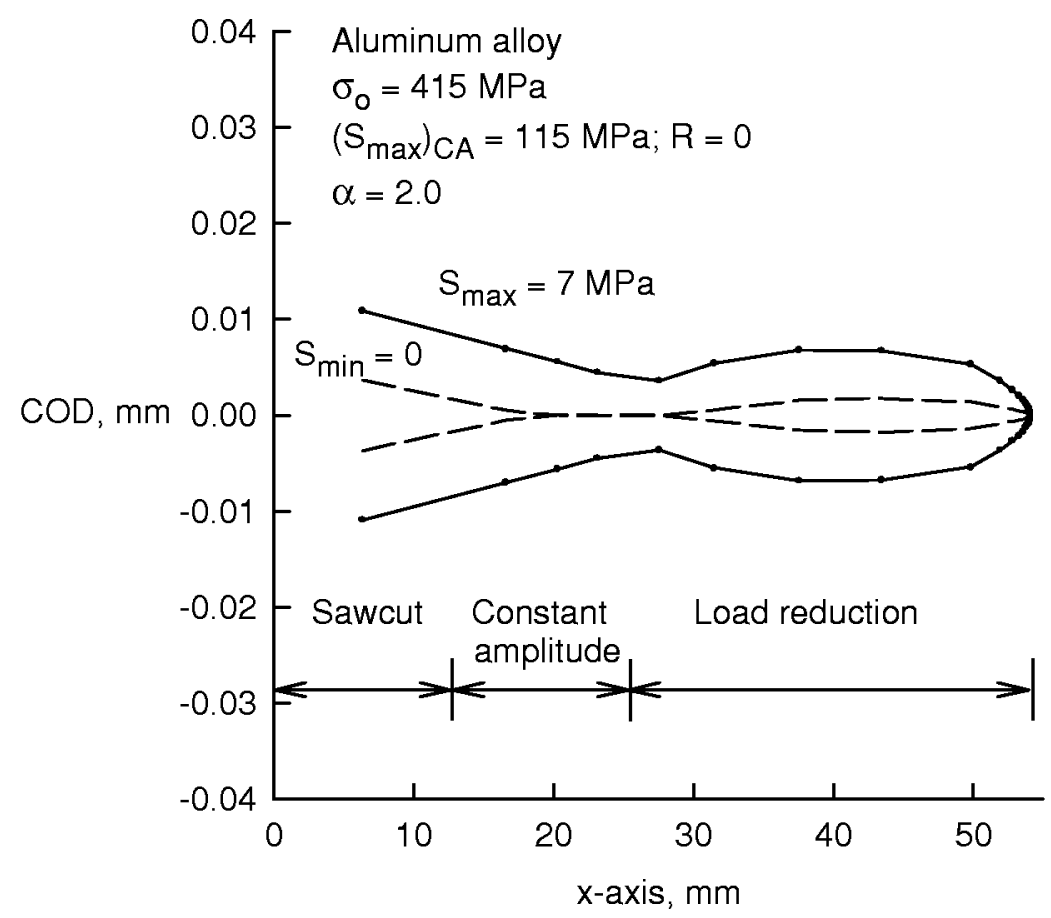

Figure 8. Crack-surface displacements after load reduction under high-constraint conditions.

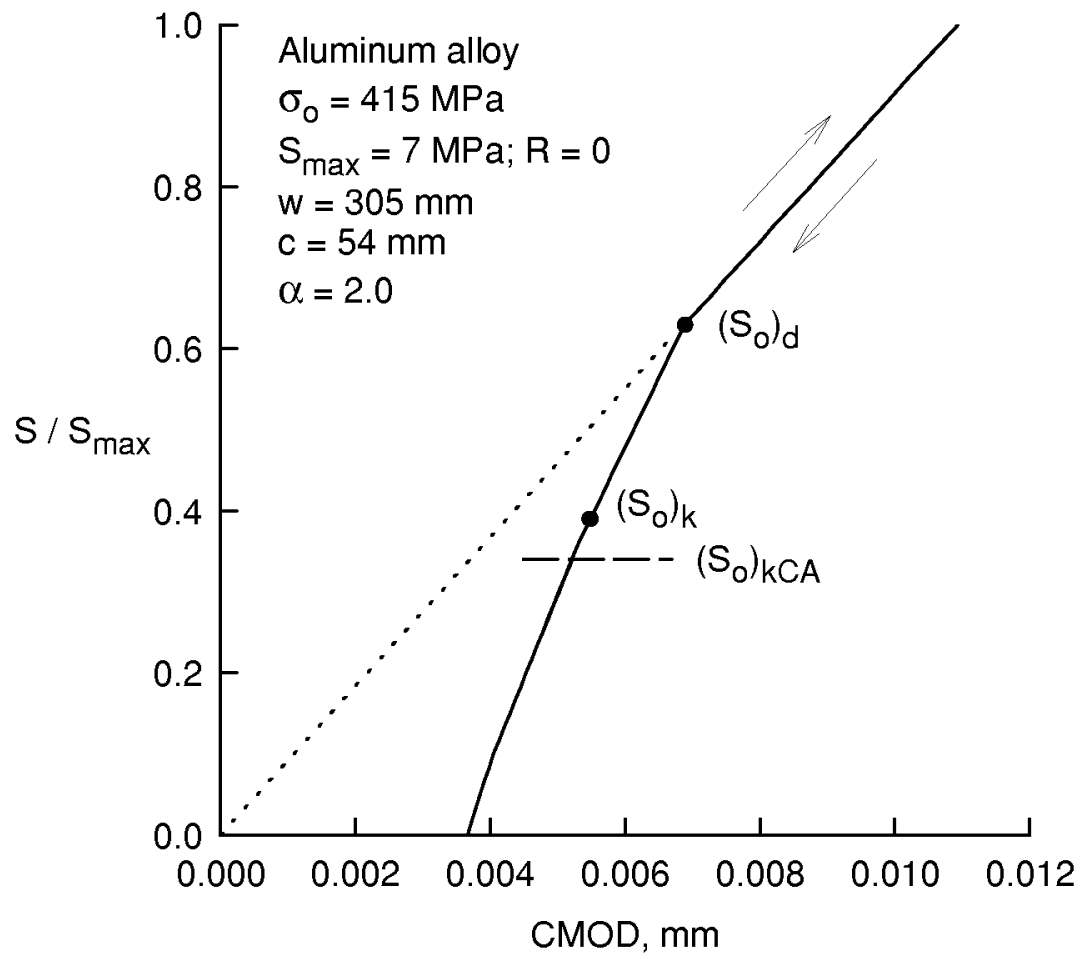

Figure 9. Remote crack-mouth-opening displacements after load reduction under highconstraint conditions. 
Incidentally, the recent work of Paris et.al [20] has indicated that under conditions of remote (or partial) closure, such as that shown in Figure 8, the appropriate opening stress to calculate the effective stress is $(2 / \pi) \mathrm{S}_{\mathrm{op}}$. The value of $\mathrm{S}_{\mathrm{op}}$ was measured using the 1 or $2 \%$ compliance-offset method. As shown herein, $S_{\mathrm{op}}$ is nearly equivalent to $\left(\mathrm{S}_{\mathrm{O}}\right)_{\mathrm{d}}$ determined from the COD analyses. Note that the ratio of $\left(\mathrm{S}_{\mathrm{o}}\right)_{\mathrm{k}}$ to $\left(\mathrm{S}_{\mathrm{o}}\right)_{\mathrm{d}}$ is 0.62 , very close to $2 / \pi$.

Crack-Opening-Stress Behavior - In the following, realistic crack-growth properties for the 2024-T3 aluminum alloy are chosen to study the effects of constraint, stress ratios, stress levels, and load-reduction rates on crack-opening stress behavior during threshold testing. For the thin-sheet alloy analyzed herein, a constraint factor of 2 was selected for low rates and 1.15 for high rates. A constraint-loss regime was assumed to occur in the crack-growth rate regime of $1 \times 10^{-7}$ to $2 \times 10^{-6} \mathrm{~m} / \mathrm{cycle}$. The contact-K analyses were used to calculate crack-opening stresses. A brief discussion on three-dimensional effects is also given.

Constraint effects - An $\mathrm{M}(\mathrm{T})$ specimen was fatigue precracked at a maximum applied stress of $115 \mathrm{MPa}$ at $\mathrm{R}=0$ under three conditions of constraint. First, analyses were conducted under constant constraint of 2 and 1.15; and then under a more realistic condition of variable constraint ( $\alpha=2$ to 1.15 during the transition from flat-to-slant crack growth). For $\alpha$ $=2$, the crack-opening stresses during the precracking stage are shown as the dashed curve in Figure 10. The solid triangular symbol shows the initial $\Delta \mathrm{K}$ value for the sawcut (no prior plastic history). After a small amount of crack growth, the $S_{\mathrm{o}} / S_{\max }$ value stabilized and the load-reduction test was initiated at a $\Delta \mathrm{K}$ of $30 \mathrm{MPa} \sqrt{\mathrm{m}}$. The crack-opening stresses during the load-reduction phase are shown as the lower solid curve. A rise in opening stresses (and threshold development) occurred at low values of $\Delta \mathrm{K}$. For the other constraint cases, the precracking stage was not shown for clarity. For $\alpha=1.15$, the results are similar to the previous case, except that the opening values are higher and the rapid rise in opening stresses occurred at a higher $\Delta \mathrm{K}$. The more realistic case shows a mixture of the other two cases. At $\mathrm{R}=0$, the threshold in 2024 aluminum alloys generally occurs at a $\Delta \mathrm{K}_{\text {th }}$ value of about 3 MPaVm.

Stress-ratio effects - Figure 11 shows the precracking stage for the more realistic crackgrowth properties ( $\alpha=2$ to 1.15 ) under constant-amplitude loading at $\mathrm{R}=0$ and 0.7 (dashed curves). Again, the triangular symbols show the initial value of $\Delta \mathrm{K}$ at the start of the test simulation. The results for the load-reduction phase at $\mathrm{R}=0$ are identical to that shown in the previous figure. It must be noted that the crack-growth simulation at $\mathrm{R}=0$ must surely violate threshold testing procedures, in that the initial $\Delta \mathrm{K}$ value at the start of the load-reduction scheme is very high. However, this may be the source of some of the 


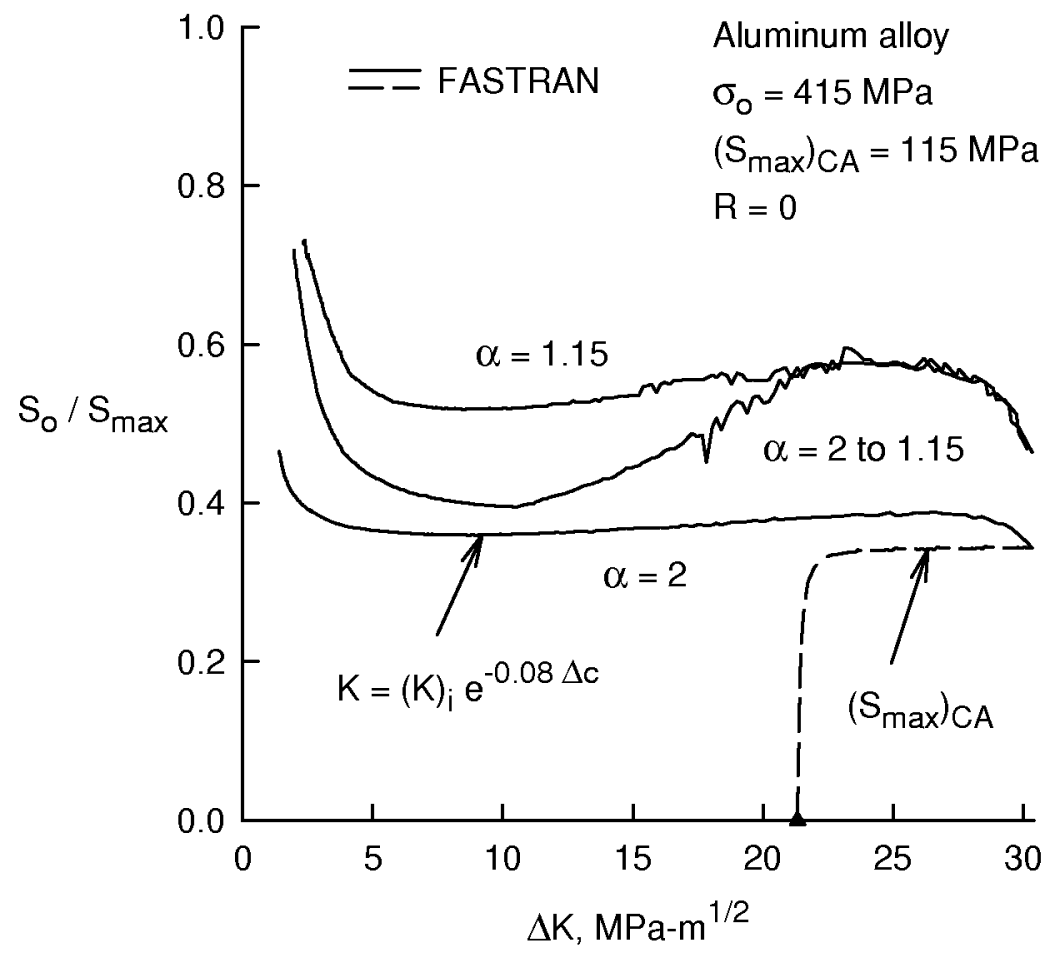

Figure 10. Calculated crack-opening-stress ratios from simulated threshold tests showing effects of crack-tip constraint.

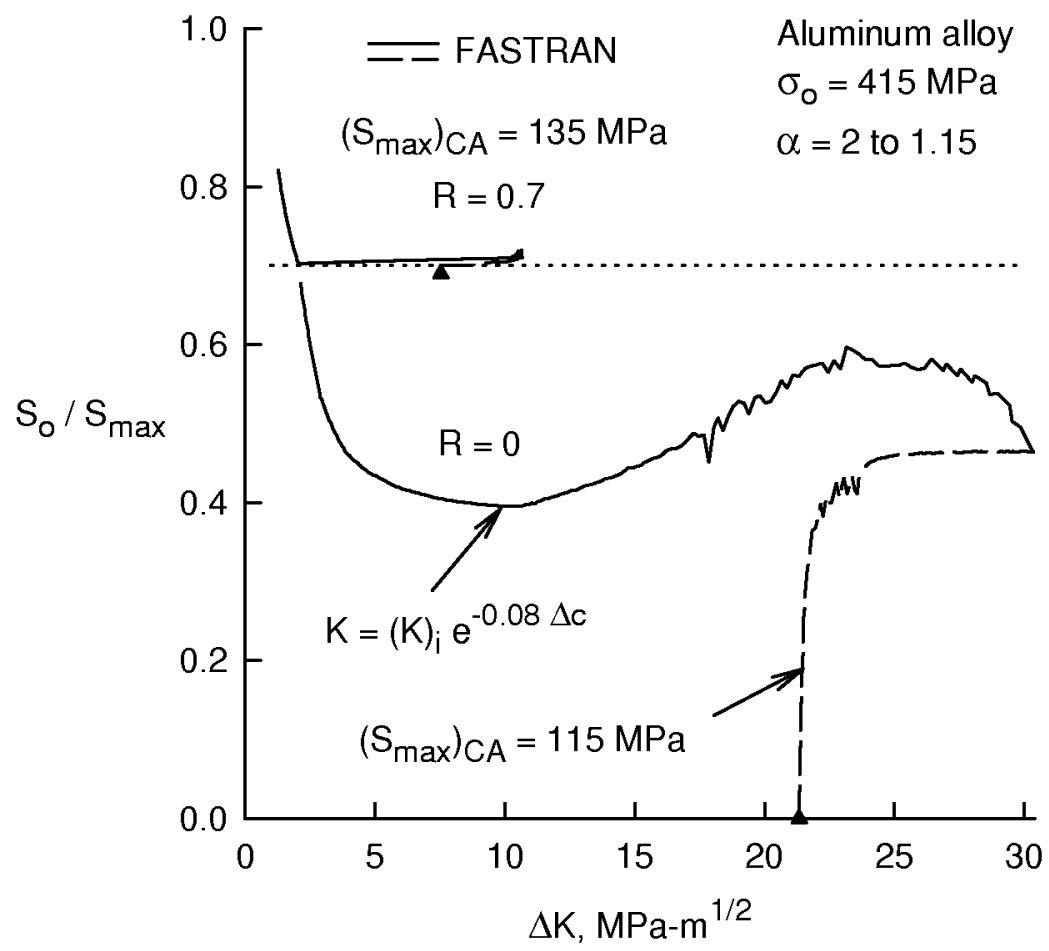

Figure 11. Calculated crack-opening-stress ratios from simulated threshold tests showing effects of stress ratio. 
high values of thresholds and specimen-size effects being reported in the literature. On the other hand, the results at $\mathrm{R}=0.7$ seem to be a more realistic test condition. To initiate cracks from sawcuts in aluminum alloys, a $\Delta \mathrm{K}$ value of about 4 to $6 \mathrm{MPa} \sqrt{\mathrm{m}}$ is generally required. The crack was precracked at $\left(\mathrm{S}_{\max }\right)_{\mathrm{CA}}$ of $135 \mathrm{MPa}$ and the $\Delta \mathrm{K}$ value at the start of loadreduction phase was about $10.5 \mathrm{MPa}{ }_{\mathrm{m}}$. The crack-opening stresses are generally near the minimum applied stress but the analyses show a rapid rise at a $\Delta \mathrm{K}$ of about $2 \mathrm{MPa} V \mathrm{~m}$. This corresponds quite closely to the development of the threshold value at $R=0.7$ for the 2024 alloy.

Stress-level effects - Because the previous low stress ratio test simulation was conducted at a very high precracking stress level, a much lower applied stress level was chosen for the second test simulation at $\mathrm{R}=0$. Again, the $\left(\mathrm{S}_{\max }\right)_{\mathrm{CA}}=115 \mathrm{MPa}$ results shown in Figure 12 are identical to that previously shown. But precracking at a low stress level (45 MPa), before the load-reduction phase, resulted in a stabilized crack-opening stress level even down to very low $\Delta \mathrm{K}$ values. Thus, under the low applied stress levels, a threshold does not develop solely due to the residual-plastic deformations. Here oxide and/or roughness contributions are needed to predict threshold development. However, residual-plastic deformations still play an important part in threshold development at low stress ratios because it is the combination of the various forms of closure that ultimately contribute to thresholds.

$\underline{\text { Load-shedding effects }}$ - Crack-growth simulations were conducted at both $\mathrm{R}=0$ and 0.7 at precracking levels of 115 and $135 \mathrm{MPa}$, respectively, using two load decay rates $\quad(-0.08$ and $-0.2 \mathrm{~mm}^{-1}$ ). The results for the high stress ratio are shown in Figure 13. These results show that the faster decay rate caused a rise to threshold to occur at a higher $\Delta \mathrm{K}$ value than the standard decay rate. The arrows indicate the value of the constraint factor. The precracking stage was conducted in the constraint-loss regime and the minimum $\alpha$ value was about 1.5. The rise in crack-opening stresses at low $\Delta \mathrm{K}$ values was caused by the residual-plastic deformations.

Three-dimensional effects - The previous results show that in-plane plasticity can cause remote or intermittent closure under plane-stress conditions or under high applied stress levels. The use of the constraint factor in a two-dimensional model is "averaging" the effects of threedimensional plastic stress states at the crack front and in the plastic wake. Three-dimensional crack-growth and closure simulations [21] under constant-amplitude loading show that substantially more closure occurs in the plane-stress regions than in the interior of a finitethickness body. 


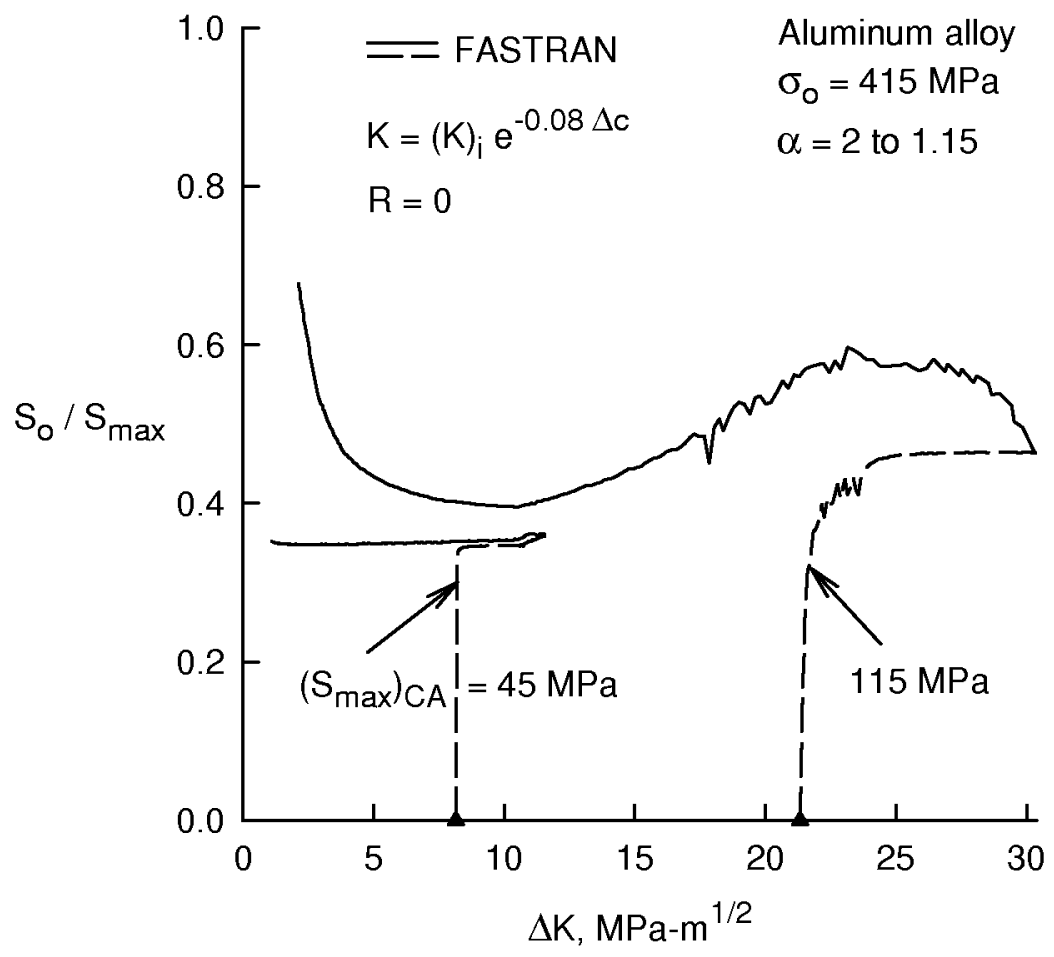

Figure 12. Calculated crack-opening-stress ratios from simulated threshold tests showing effects of stress level.

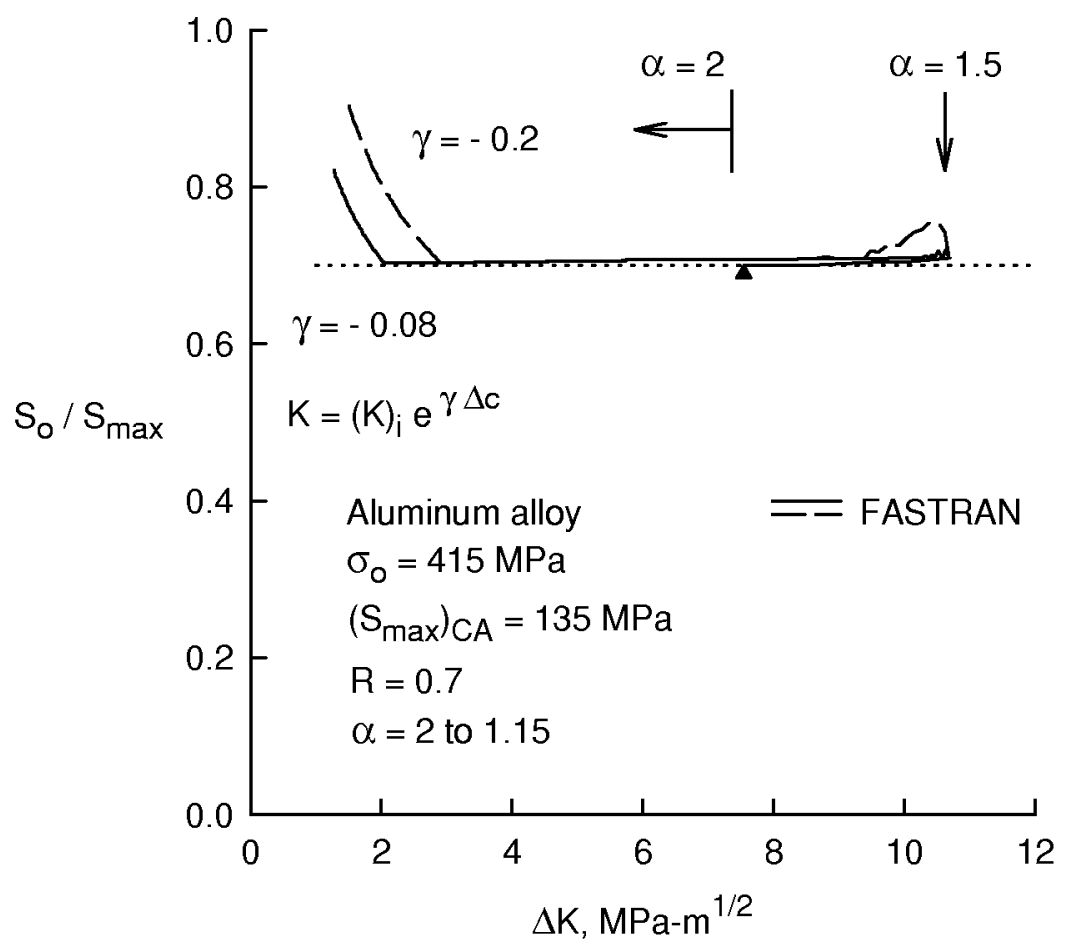

Figure 13. Calculated crack-opening-stress ratios from simulated threshold tests showing effects of load-reduction rates. 
Apparently, the plane-stress regions near the free surfaces of a specimen also play an important role on crack-closure behavior under variable-amplitude loading. McEvily [22] found in a test on a 6061 aluminum alloy $(B=13 \mathrm{~mm})$ that a spike overload caused significant crack-growth delay. When he machined $25 \%$ of the thickness from each surface (after the application of the spike overload), he found very little crack-growth delay. Thus, the crackclosure effect under spike overloads is predominantly a surface phenomenon. Do the planestress regions cause more contact in a threshold test? To help answer this question, threedimensional elastic-plastic analyses are required and this must await a future study.

\section{APPLICATION OF CRACK CLOSURE ANALYSES TO TEST DATA}

The crack-closure model analysis will be applied to test data on thin-sheet 2024-T3 aluminum alloy. The threshold tests were conducted on $\mathrm{M}(\mathrm{T})$ specimens using the ASTM load-reduction procedure [16,23]. In addition, test and analyses will also be compared for a constant- $\mathrm{K}_{\max }$ test [16].

\section{Constant-Amplitude/Load-Reduction Tests and Analyses}

Hudson [24] conducted constant-amplitude fatigue-crack-growth rate tests on a 2024-T3 aluminum alloy $(\mathrm{B}=2.3 \mathrm{~mm})$ material over a wide range in stress ratio. Later, Phillips [23] conducted threshold tests on the same material to obtain test data at very low crack-growth rates. Recently, Donald and Paris [16] conducted a test on a similar thin-sheet 2024 alloy using a constant $\mathrm{K}_{\max }$ test. The constant-amplitude crack-opening stress equations [18] with a constraint factor of 1.73 (rates less than $1 \times 10^{-7} \mathrm{~m} / \mathrm{cycle}$ ) [25] were used to calculate the effective stress-intensity factor for these data. The results from Hudson and Phillips data are plotted on Figure 14 and show that the data correlates quite well, even down to threshold. The $\mathrm{K}_{\max }$ test of Donald and Paris agreed for rates greater than $2 \times 10^{-9} \mathrm{~m} / \mathrm{cycle}$, but resulted in lower $\Delta \mathrm{K}_{\text {eff }}$ values than the constant- $\mathrm{R}$ tests as the threshold is approached. The constant- $\mathrm{R}$ tests showed a slight trend with stress ratio at threshold. The higher stress ratio test had a lower $\Delta \mathrm{K}_{\mathrm{th}}$ than the low stress ratio tests. Phillips [23] measured a rise in crack-opening stresses for the low $\mathrm{R}$ tests, but he did not measure a rise for the $\mathrm{R}=0.7$ test. However, he observed in all cases that a higher load was required to re-initiate growth of the dormant crack even at the high stress ratio. This may indicate that an accumulation of oxide raised the opening load even for the high stress ratio test. Interestingly, the solid lines on Figure 14, below rates of $1 \times 10^{-9} \mathrm{~m} / \mathrm{cycle}$, is a baseline fits to small-crack data for this alloy [26]; and these results generally agree with the constant- $\mathrm{K}_{\max }$ test data. 


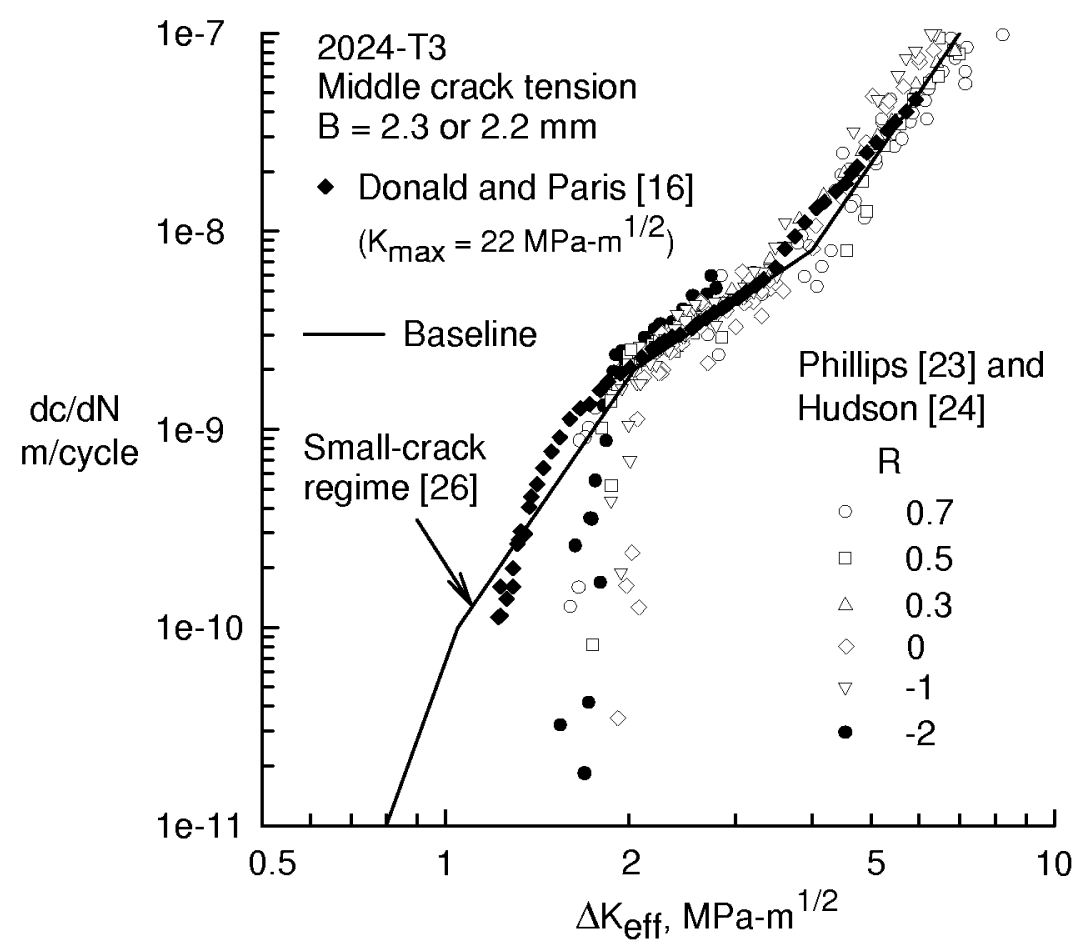

Figure 14. Effective stress-intensity factor against crack-growth rates for 2024-T3 at very low rates showing small-crack regime and constant- $\mathrm{K}_{\max }$ test results.

A comparison of measured and calculated crack-opening stresses at $\mathrm{R}=0$ are shown in Figure 15. The solid symbols are measured values from Phillips [23] using the Elber method [27] and the open symbols are opening values determined from Hudson's data using an indirect method [6]. (The indirect method finds the value of opening stress at $\mathrm{R}=0$ to correlate with the baseline $\Delta \mathrm{K}_{\mathrm{eff}}$-rate curve.) The solid curve is the predicted $\mathrm{K}_{\mathrm{o}}$ values from the closure model. Because the precracking $\Delta \mathrm{K}$ levels were less than about $5 \mathrm{MPa} \sqrt{\mathrm{m}}$, the analysis did not predict a threshold from residual-plastic deformations. The sharp knee shown by the test data at a $\Delta \mathrm{K}$ of $4 \mathrm{MPa} \vee \mathrm{m}$ is the development of the threshold. Based on the literature, oxide accumulation is suspected to cause the threshold development. The dashed lines are based on constant constraint calculations from plane-stress to plane-strain conditions. The sharp knee at a $\Delta \mathrm{K}$ level of about $12 \mathrm{MPa} V_{\mathrm{m}}$ is associated with the beginning of the constraint-loss regime.

Figure 16 shows the crack-opening values from the Donald and Paris data [16] at $R=0$ and 0.7 using the indirect method (symbols). The $K_{\max }$ test results at rates lower than about

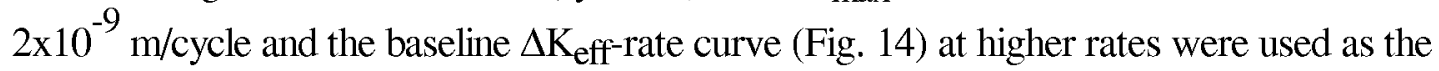
baseline data. Because the $\mathrm{R}=0.7$ and $\mathrm{K}_{\max }$ results differed at low rates, the indirect method produced a sharp rise in opening stresses at threshold for the $\mathrm{R}=0.7$ data (square 


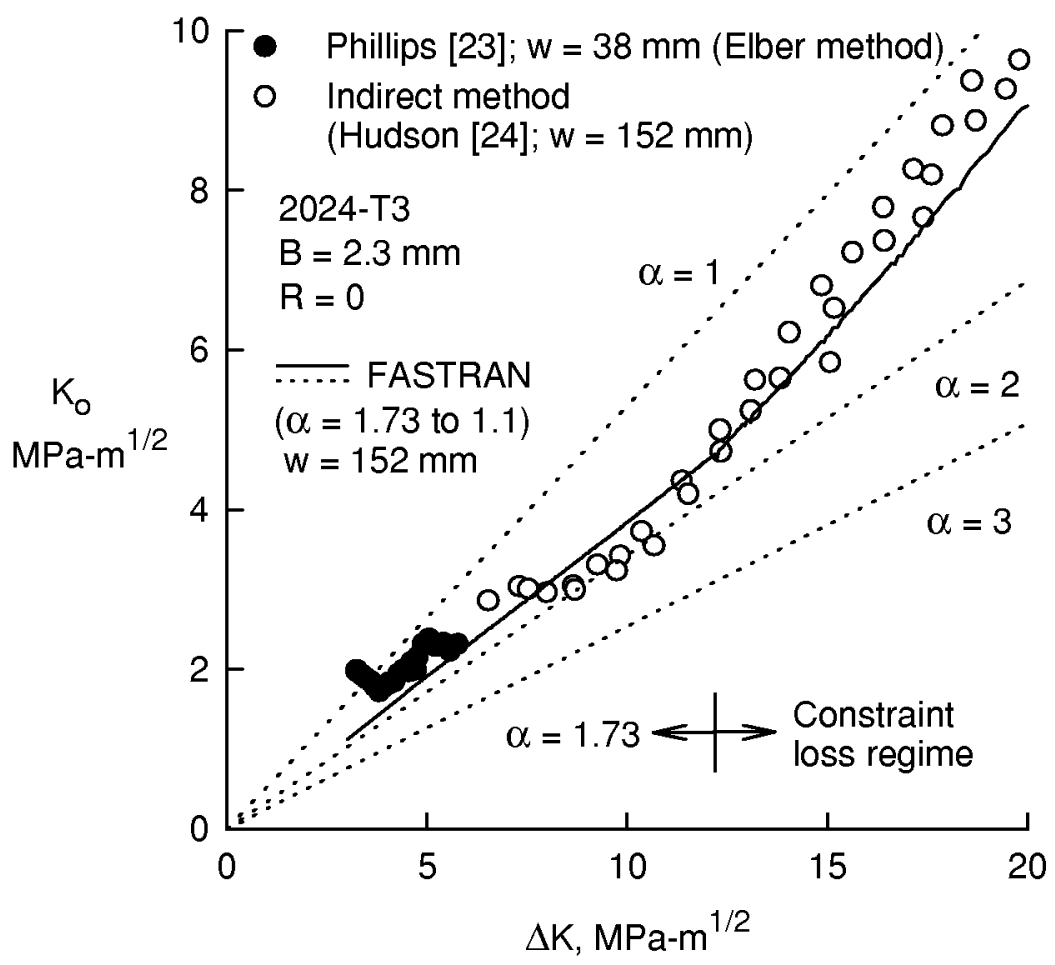

Figure 15. Crack-opening stress-intensity factors for 2024-T3 aluminum alloy at $\mathrm{R}=0$ from measured, indirect method, and model calculations.

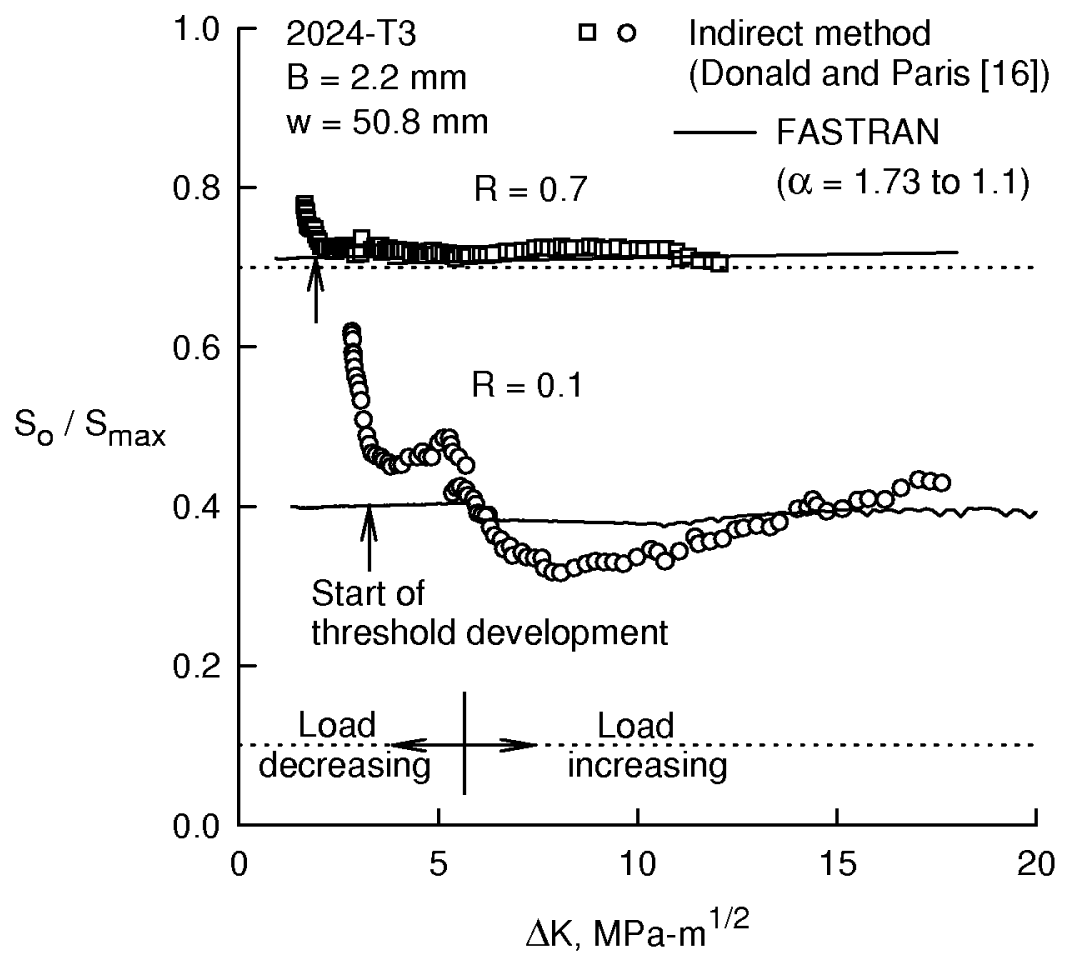

Figure 16. Crack-opening stress ratios for 2024-T3 aluminum alloy at low and high stress ratios from indirect method and model calculations. 
symbols). The low $\mathrm{R}$ results also showed a sharp rise at threshold. The solid curves show the calculations from the closure model for load-decreasing and load-increasing tests. Again, the model did not show a rise in opening loads because the $\Delta \mathrm{K}$ level at the start of each test was low (about $6 \mathrm{MPa} \sqrt{\mathrm{m}}$ ). For these cases, the contact-K and COD analyses gave essentially the same results. Remote displacement gages are most likely unable to measure the very small amount of closure for the high-stress ratio tests. But under high-R conditions, the calculated opening load is very near to the minimum applied stress level. Thus, a small amount of interference from roughness or oxide-accumulation may cause a threshold to develop.

To study why the model did not predict a rise in the opening stresses, the near crack-tipopening displacements at the start of the test threshold development (shown by the vertical arrows in Fig. 16) are shown in Figures 17 and 18. The local COD's are shown in Figure 17(a) at maximum load and Figure 17(b) at minimum load. The stress-intensity factor range $\Delta \mathrm{K}(2$ $\mathrm{MPa} \vee \mathrm{m}$ ) was slightly higher than the $\mathrm{R}=0.7$ threshold value that would have developed for the 2024-T3 alloy (about 1.56 MPa $V_{\mathrm{m}}[16,23]$ ). The crack length and plastic-zone size are as indicated on the figure. The solid curve shows the crack-surface profile. The dashed curve shows the boundary between elastic and plastic material. Even under the high-constraint conditions and at the low stress-intensity factor level, the residual-plastic deformations contribute greatly to the final crack-surface profile. The CTOD at maximum load was 0.05 $\mu \mathrm{m}$. At minimum load, the crack-tip region is closed over a very small area $\left(S_{\alpha} / S_{\max }=0.71\right)$. Because tests indicate that a threshold would have developed under these conditions, the other forms of closure may be contributing to threshold development. In considering oxide-induced closure, what oxide-layer thickness would have been required to influence crack closure at minimum load? For the 2024-T3 aluminum alloy at a high relative humidity (95\%), Vasudevan and Suresh [17] measured peak oxide thicknesses of $0.02 \mu \mathrm{m}$ at $\mathrm{R}=0.33$. But oxide-layer thicknesses are expected to be smaller at the high stress ratio condition. However, the cracksurface displacements would also have been smaller than those shown in the figure at $\Delta \mathrm{K}_{\mathrm{th}}$. Thus, residual-plastic deformations and oxide accumulation could be plausible explanations for threshold development. The relative contribution of crack-surface roughness to threshold development is difficult to assess.

The crack-tip-surface displacements at maximum load for the $\mathrm{R}=0.1$ test simulation are shown in Figure 18. The CTOD was $0.07 \mu \mathrm{m}$. The residual-plastic deformations (difference between solid and dashed curves) were of the same order-of-magnitude as the near crack tip COD's. At minimum load, the crack surfaces were closed over a large region (not shown). Thus, a peak oxide-layer thickness of $0.02 \mu \mathrm{m}$ [17], in combination with the 


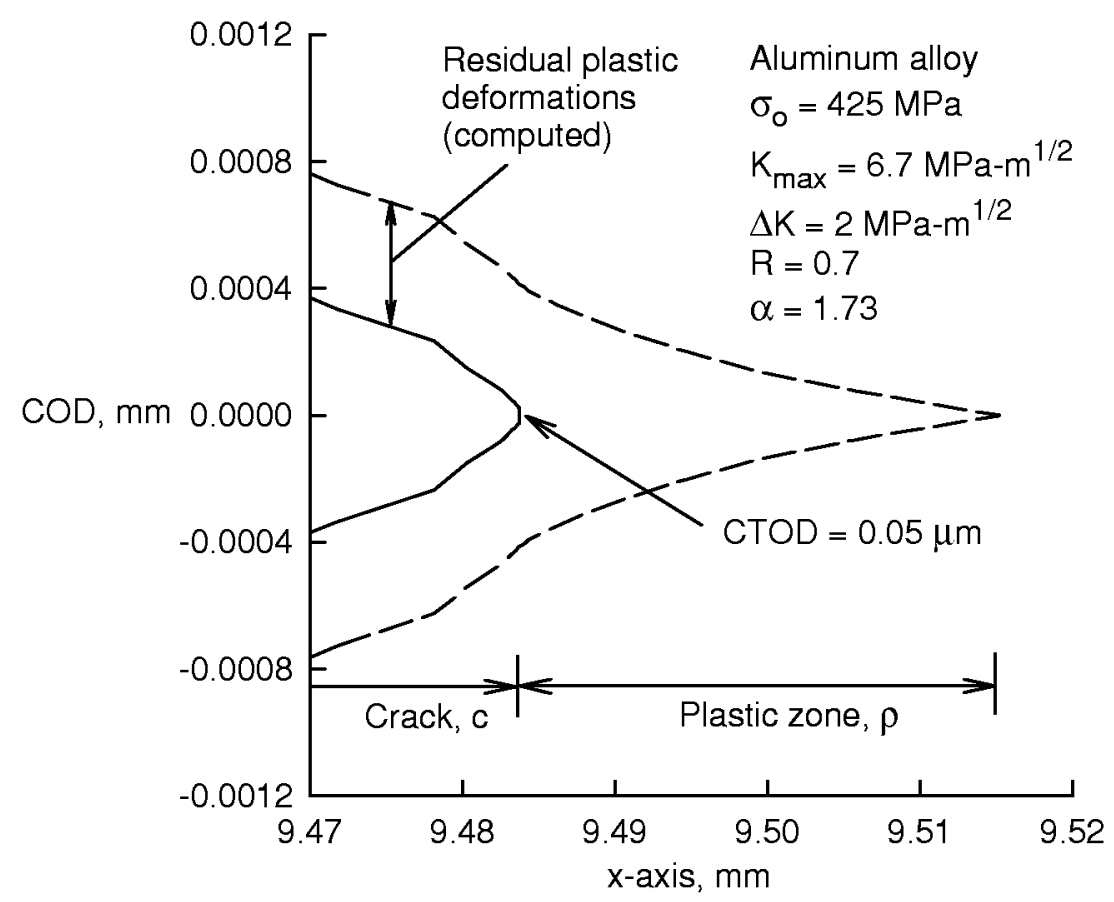

(a) Maximum load

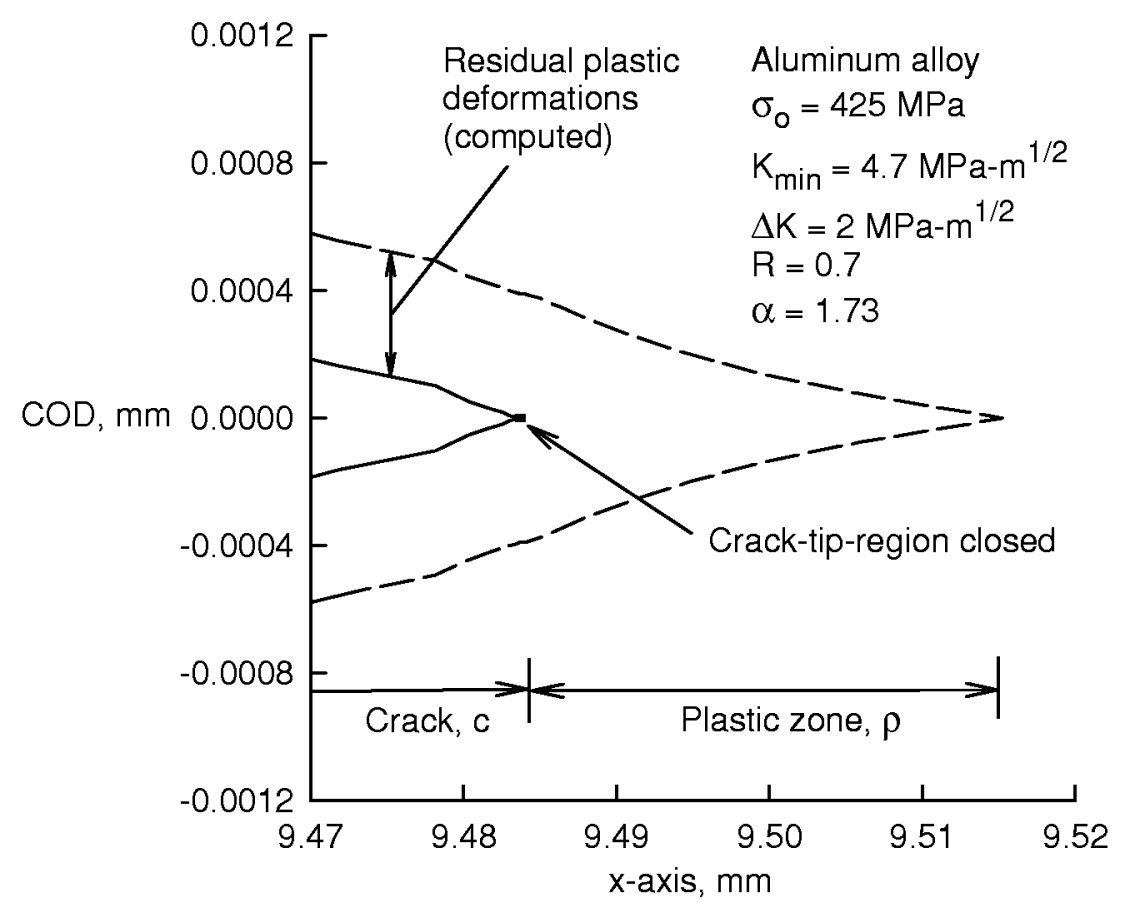

(b) Minimum load

Figure 17. Crack-tip-surface displacements showing residual-plastic deformations and plasticzone size near threshold conditions at high-stress ratio. 


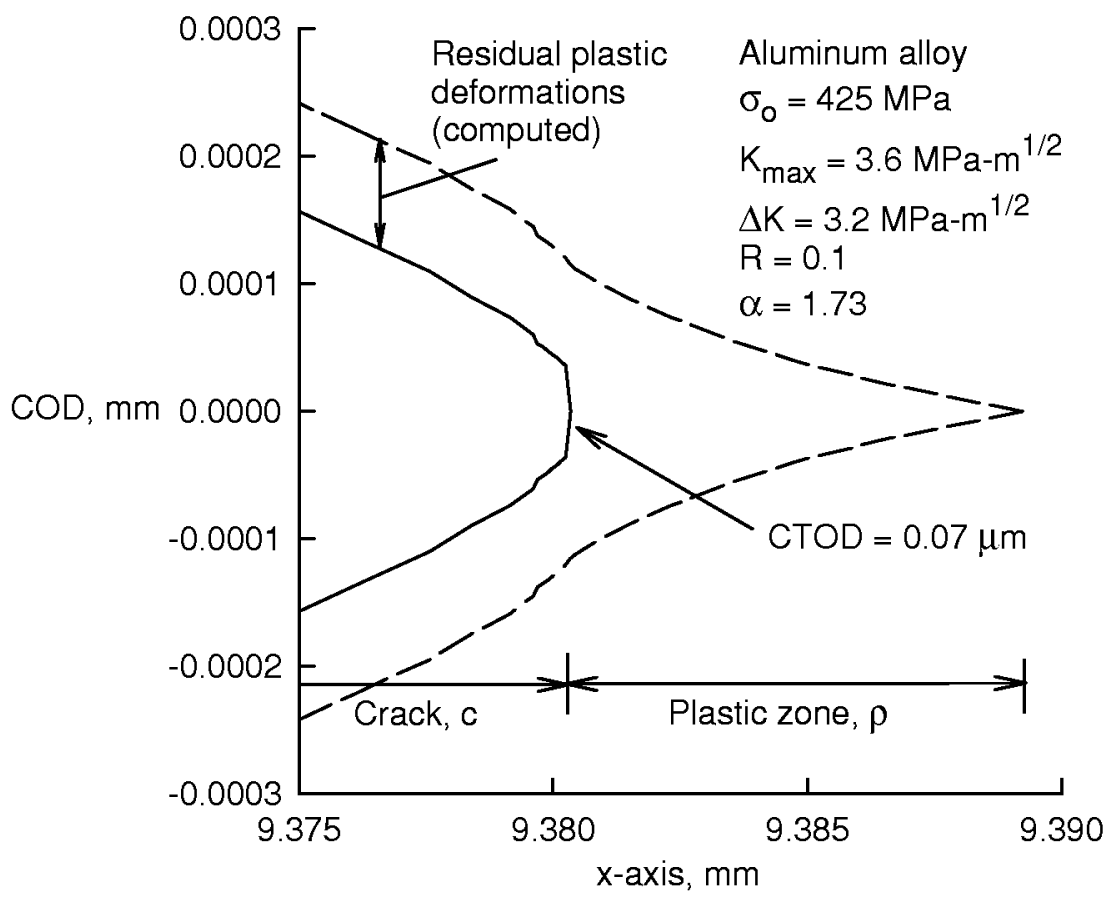

Figure 18. Crack-tip-surface displacements at maximum load showing residual-plastic deformations and plastic-zone size near threshold conditions at a low stress ratio.

residual-plastic deformations, would have had a large influence on calculated crack-opening loads and threshold development.

\section{Constant-K $K_{\max }$ Test and Analysis}

The $\mathrm{K}_{\max }$ test [28] has been proposed as an alternative test to obtain low crack-growth rate data. A crack-growth and closure analysis of the $\mathrm{K}_{\max }$ test conducted by Donald and Paris [16] is shown in Figure 19. The upper dashed line is the $\mathrm{K}_{\max }(22 \mathrm{MPa} / \mathrm{m})$ value and the lower dashed curve is the $K_{\text {min }}$ values. The initial notch half-length was $c_{n}$ and the crack half-length $\mathrm{c}_{\mathrm{i}}$ denotes the start of the increasing $\mathrm{K}_{\min }$ test. The solid curve shows the calculations from the model. At an stress ratio of about 0.8 , the crack surfaces became fully open at the minimum stress-intensity factor (solid symbol).

At the end of the test simulation, the $R$ value was about 0.95 and the $\Delta K$ value was 1.2 $\mathrm{MPa} \vee \mathrm{m}$. Figure 20 shows the local crack-tip-surface displacements at minimum load under these conditions. The solid curves are the crack surfaces and the dashed curves show the boundary between the elastic and plastic regions. The crack-tip-opening displacement was about $0.14 \mu \mathrm{m}$, nearly an order-of-magnitude larger than the expected peak oxide thicknesses [17] even under a relative high humidity. Thus, oxide-induced closure should not be an issue. Again the contribution of crack-surface roughness is difficult to assess. But the $\mathrm{K}_{\max }$ test results agreed reasonably well with the small-crack data on this alloy (see 


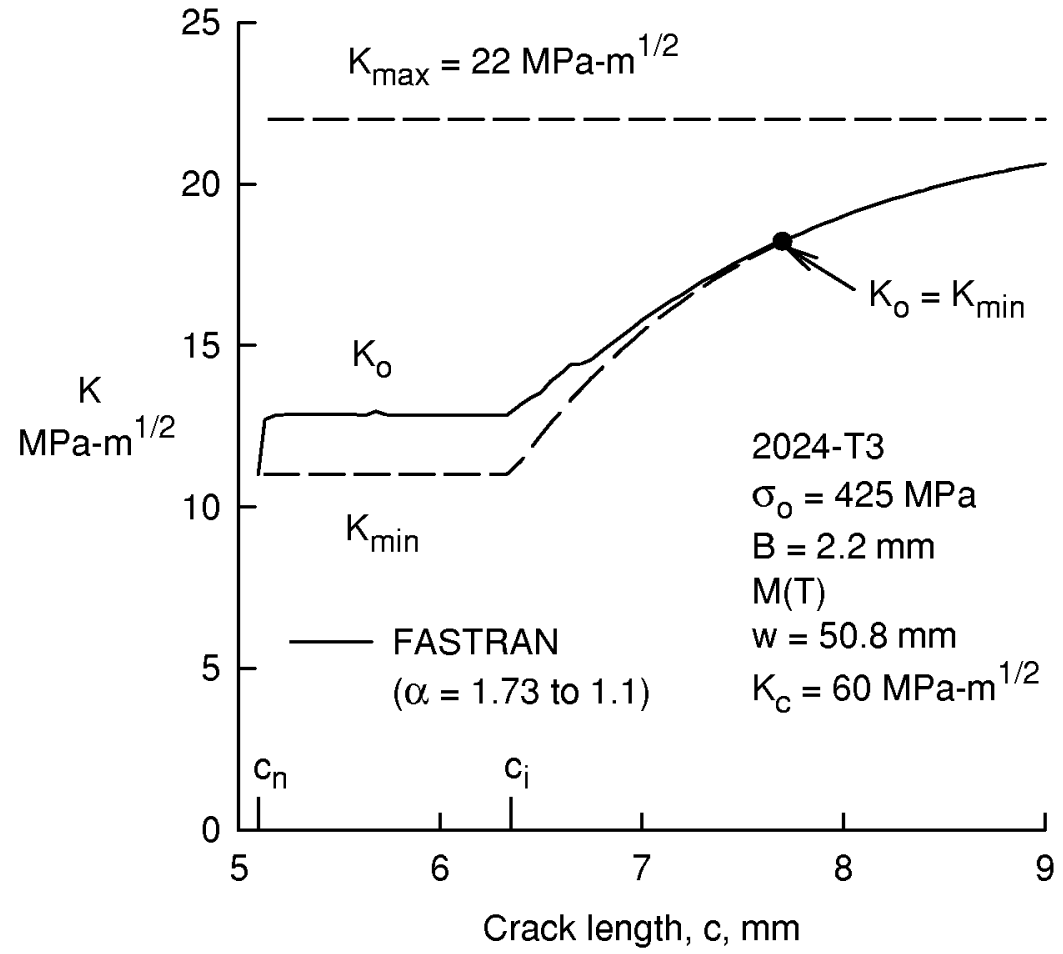

Figure 19. Calculated crack-opening stress-intensity factors for constant- $\mathrm{K}_{\max }$ test.

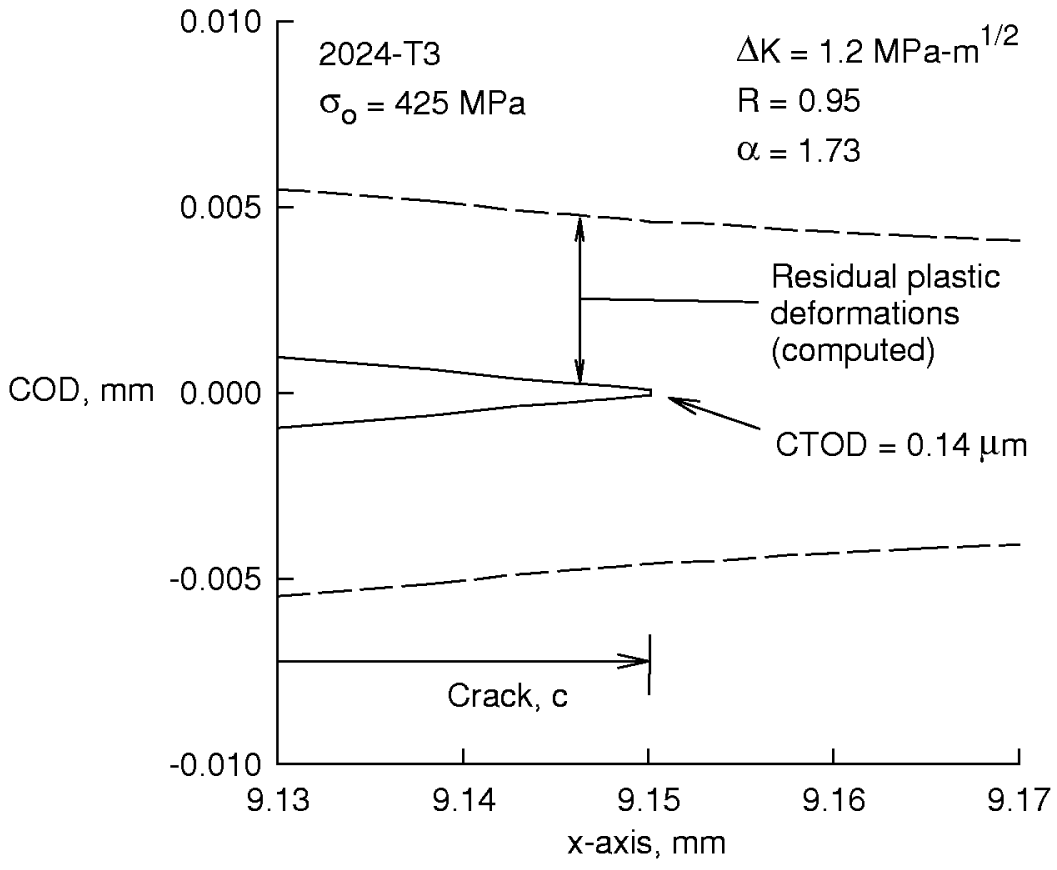

Figure 20. Crack-tip-surface displacements at minimum load under constant- $K_{\max }$ testing near threshold conditions. 
Fig. 14). Note that the residual-plastic deformations were about 50 times larger than the cracktip-opening displacement.

\section{CONCLUSIONS}

A plasticity-induced crack-closure model was used to simulate fatigue-crack growth and closure under constant-amplitude, load-reduction, load-increasing, and constant- $\mathrm{K}_{\max }$ testing on thin-sheet 2024-T3 aluminum alloy. The following conclusions were made:

(1) Crack-opening stresses under constant-amplitude loading computed from contact-K analyses were nearly equal to those computed from a contact crack-opening displacement (COD) method, but under threshold testing (load-reduction) simulations, the opening stresses from the contact-K analyses were equal to or lower than those from the contactCOD analyses.

(2) For some remote (partial) closure situations, crack-opening stresses computed from remote displacements, using the 1 or $2 \%$ compliance-offset method, agreed with erroneously high values computed from the contact-COD method, but comparisons of crack-growth predictions with measurements tend to support crack-opening stresses from the contact-K analyses.

(3) Under low $(\mathrm{R}=0)$ and high $(\mathrm{R}=0.7)$ stress-ratio load-reduction simulations, analyses produce residual-plastic deformations that cause remote closure and threshold development for low-constraint (plane-stress) behavior and at high applied stress levels (applied-stress-to-flow-stress ratios greater than about 0.25). For plane-strain conditions and low applied stress levels, remote closure and threshold development were not observed.

(4) Under low $(\mathrm{R}=0)$ and high $(\mathrm{R}=0.7)$ stress-ratio load-reduction simulations, analyses produce residual-plastic deformations near threshold conditions that were of the same order-of-magnitude as the crack-tip-opening displacements. But additional contributions from roughness and/or oxide-fretting debris are required to develop thresholds.

(5) Constant- $\mathrm{K}_{\max }$ test simulations produce closure-free crack surfaces from residualplastic deformations at the high stress ratio ( $\mathrm{R}>0.8$ ) conditions; and the crack-tip opening displacements at minimum loads were an order-of-magnitude larger than expected peak oxide thicknesses for 2024 aluminum alloys. Thus, contributions from oxide-fretting debris may not have an influence on threshold development. 


\section{REFERENCES}

[1] Paris, P. C., "Testing for Very Slow Growth of Fatigue Cracks," Closed Loop Magazine, MTS Systems Corporation, Vol. 2, No. 5, 1970.

[2] Saxena, A., Hudak, S. J., Jr., Donald, J. K. and Schmidt, D. W., “ComputerControlled Decreasing Stress Intensity Technique for Low Rate Fatigue Crack Growth Testing," Journal of Testing and Evaluation, Vol. 6, No. 3, 1978, pp. 167174.

[3] Elber, W., "The Significance of Fatigue Crack Closure," Damage Tolerance in Aircraft Structures, ASTM STP 486, American Society for Testing and Materials, 1971, pp. 230-242.

[4] Paris, P. C., Bucci, R. J., Wessel, E. T., Clark, W. G. and Mager, T. R., "Extensive Study of Low Fatigue Crack Growth Rates in A533 and A508 Steels, " ASTM STP513, 1972, pp. 141-176.

[5] Walker, N. and Beevers, C. J., "A Fatigue Crack Closure Mechanism in Titanium," Fatigue of Engineering Materials and Structures, Vol. 1, No. 1, 1979, pp. 135-148.

[6] Newman, J. C., Jr., "A Crack-Closure Model for Predicting Fatigue Crack Growth under Aircraft Spectrum Loading," Methods and Models for Predicting Fatigue Crack Growth under Random Loading, ASTM STP 748, J. B. Chang and C. M. Hudson, Eds., American Society for Testing and Materials, 1981, pp. 53-84.

[7] Newman, J. C., Jr., "FASTRAN-II - A Fatigue Crack Growth Structural Analysis Program," NASA TM 104159, February 1992.

[8] Dugdale, D. S., "Yielding of Steel Sheets containing Slits," Journal of the Mechanics and Physics of Solids, Vol. 8, 1960, pp. 100-104.

[9] Blom, A.; Wang, G. and Chermahini, R. G., "Comparison of Crack Closure Results Obtained by 3D Elastic-Plastic FEM and Modified Dugdale Model," Localized Damage: Computer-Aided Assessment and Control, M. H. Aliabadi et al., Eds., Computational Mechanics Publications, Springer-Verlag, Berlin, 1990, pp. 57-68.

[10] Newman, J. C., Jr., "A Nonlinear Fracture Mechanics Approach to the Growth of Small Cracks," Behaviour of Short Cracks in Airframe Materials, AGARD CP-328, 1983, pp. 6.1-6.26.

[11] Newman, J. C., Jr., "Finite-Element Analysis of Crack Growth under Monotonic and Cyclic Loading," Cyclic Stress-Strain and Plastic Deformation Aspects of Fatigue Crack Growth, ASTM STP 637, American Society for Testing and Materials, 1977, pp. 56-80. 
[12] Newman, J. C., Jr., "Fracture Analysis of Various Cracked Configurations in Sheet and Plate Materials," Properties Related to Fracture Toughness, ASTM STP 605, American Society for Testing and Materials, 1976, pp. 104-123.

[13] Newman, J. C., Jr., "An Evaluation of Plasticity-Induced Crack-Closure Concept and Measurement Methods," Advances in Fatigue Crack Closure Measurement and Analysis, ASTM STP 1343, R. C. McClung and J. C. Newman, Jr., Eds., American Society for Testing and Materials, 1998.

[14] Ohta, A., Kosuge, M. and Sasake, E., "Fatigue Crack Closure Over the Range of Stress Ratios from - 1 to 0.8 Down to Stress Intensity Factor Threshold Level in HT80 Steel and SUS 304 Stainless Steel," International Journal of Fracture, Vol. 14, No. 3, 1978, pp. 251-264.

[15] Minakawa, K. and McEvily, A. J., "On Crack Closure in the Near-Threshold Region," Scripta Metallurgica, Vol. 15, 1981, pp. 633-636.

[16] Donald, J. K. and Paris, P. C., "An Evaluation of $\Delta \mathrm{K}_{\mathrm{eff}}$ Estimation Procedures on 6061-T6 and 2024-T3 Aluminum Alloys," Proceedings of Fatigue Damage of Structural Materials II, Cape Cod, MA, September 7-11, 1998.

[17] Vasudevan, A. K. and Suresh, S., "Influence of Corrosion Deposits on NearThreshold Fatigue Crack Growth Behavior in 2XXX and 7XXX Series Aluminum Alloys," Metallurgical Transactions A, Vol. 13A, December 1982, pp. 2271-2280.

[18] Newman, J. C., Jr., "A Crack Opening Stress Equation for Fatigue Crack Growth," International Journal of Fracture, Vol. 24, 1984, R131-R135.

[19] Garr, K. R. and Hresko, G. C., III, "A Size Effect on the Fatigue Crack Growth Rate Threshold of Alloy 718," Fatigue Crack Growth Thresholds, Endurance Limits, and Design, ASTM STP 1372, J. C. Newman and R. S. Piascik, Eds., American Society for Testing and Materials, West Conshohocken, PA, 1999.

[20] Paris, P. C., Tada, H. and Donald, J. K., "Service Load Fatigue Damage - A Historical Perspective," Proceedings of Fatigue Damage of Structural Materials II, Cape Cod, MA, September 7-11, 1998.

[21] Chermahini, R. G., Shivakumar, K. N. and Newman, J. C., Jr., "Three-Dimensional Finite-Element Simulation of Fatigue Crack Growth and Closure," Mechanics of Fatigue Crack Closure, ASTM STP 982, J. C. Newman, Jr. and W. Elber, Eds., American Society for Testing and Materials, 1988, pp. 398-413.

[22] McEvily, A. J., "Current Aspects of Fatigue," Metal Science, August/September 1977, p. 284. 
[23] Phillips, E. P., "The Influence of Crack Closure on Fatigue Crack Growth Thresholds in 2024-T3 Aluminum Alloy," Mechanics of Fatigue Crack Closure, ASTM STP 982, J. C. Newman, Jr. and W. Elber, Eds., American Society for Testing and Materials, 1988, pp. 505-515.

[24] Hudson, C. M., "Effect of Stress Ratio on Fatigue-Crack Growth in 7075-T6 and 2024-T3 Aluminum Alloy Specimens," NASA TN D-5390, 1969.

[25] Newman, J. C., Jr., Swain, M. H. and Phillips, E. P., "An Assessment of the SmallCrack Effect for 2024-T3 Aluminum Alloy," Small Fatigue Cracks, R. O. Ritchie and J. Lankford, eds., The Metallurgical Society, Inc., 1986, pp. 427-451.

[26] Newman, J. C., Jr., Harris, C. E., James, M. A. and Shivakumar, K. N., "FatigueLife Prediction of Riveted Lap-Splice Joints using Small-Crack Theory," Fatigue in New and Ageing Aircraft, R. Cook and P. Poole, eds., EMAS Publishing, UK, 1997, pp. 523-552.

[27] Elber, W., "Crack-Closure and Crack-Growth Measurements in Surface-Flawed Titanium Alloy Ti-6Al-4V," NASA TN D-8010, September 1975.

[28] Herman, W. A., Hertzberg, R. W., Newton, C. H. and Jaccard, R., "A Reevaluation of Fatigue Threshold Test Methods," Fatigue '87, Third International Conference on Fatigue and Fatigue Thresholds, Vol. II, 1987, pp. 819-828. 


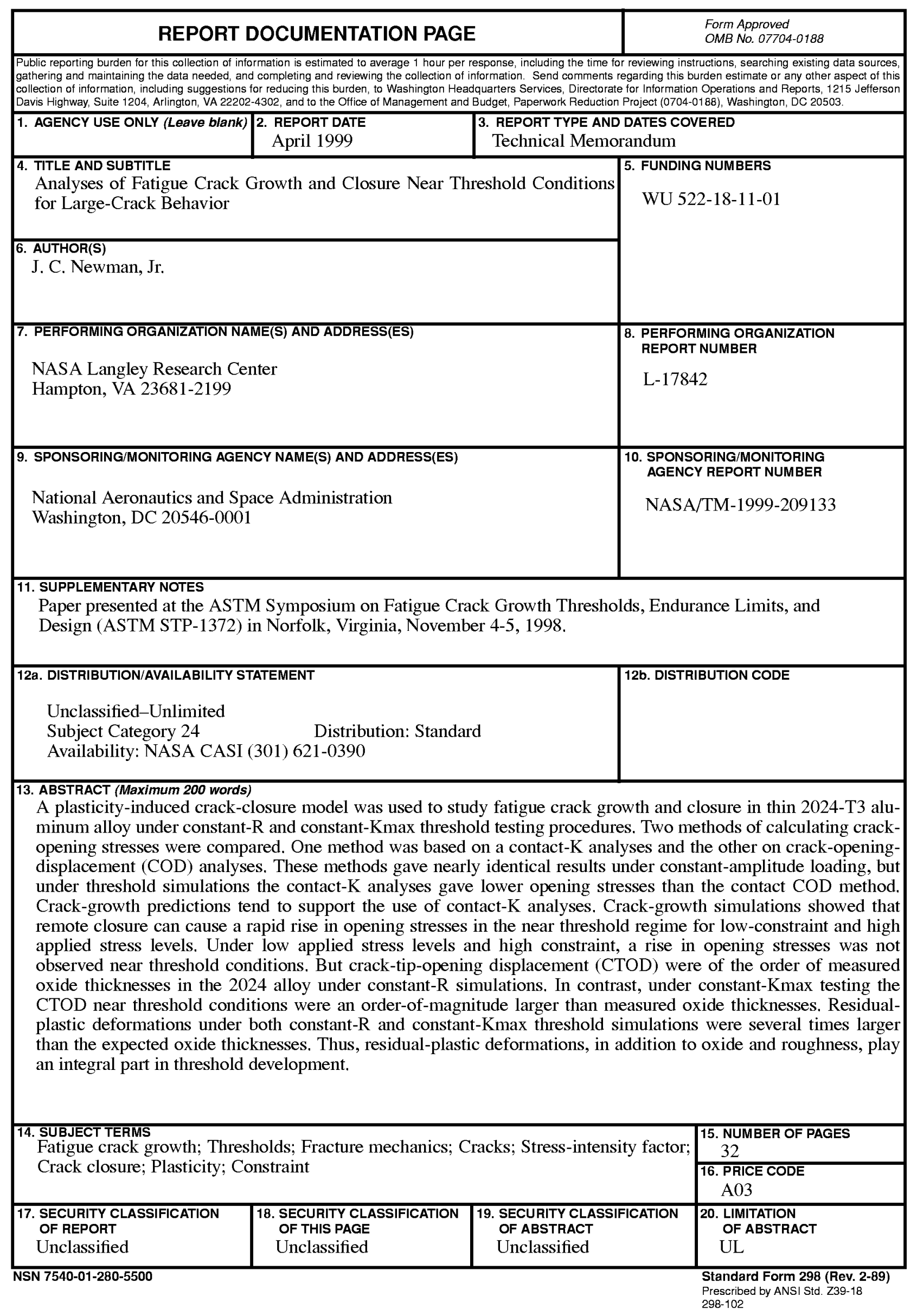

